\title{
Environmentally triggered evolutionary cascade across trophic levels in an experimental phage-bacteria-insect system
}

\author{
Matthieu Bruneaux ${ }^{1 \dagger}$, Roghaieh Ashrafi ${ }^{1}$, Ilkka Kronholm ${ }^{1}$, \\ Anni-Maria Örmälä-Odegrip ${ }^{2}$, Juan A. Galarza ${ }^{1}$, Chen Zihan ${ }^{1}$, \\ K. S. Mruthyunjay ${ }^{1}$, Tarmo Ketola ${ }^{1}$
}

November 20, 2019

\footnotetext{
${ }^{1}$ Department of Biological and Environmental Science, University of Jyväskylä, Finland ${ }^{2}$ Department of Laboratory Medicine, Karolinska Institute, Stockholm, Sweden ${ }^{\dagger}$ Corresponding author: Matthieu Bruneaux, matthieu.bruneaux@ens-lyon.org
} 


\section{2}

\begin{abstract}
Environmental changes can cause strong cascading effects in species communities due to altered biological interactions between species (Zarnetske et al., 2012). Highly specialized interactions arising from the co-evolution of hosts and parasites, such as bacteria and phages, and short generation times of these species could rapidly lead to considerable evolutionary changes in their biotic interactions (Kerr, 2012; Buck and Ripple, 2017), with potential large-scale ramifications to other trophic levels. Here we report experimental evidence of cascading environmental effects across trophic levels in an experimental system where phagebacteria coevolution in an abiotically altered environment cascaded on bacterial virulence in an insect host. We found that the lytic cycle of the temperate phage KPS20 induced at low temperatures led to selection in the bacterial host Serratia marcescens that tempered the likelihood of triggering the phage's lytic cycle. These changes in $S$. marcescens concomitantly attenuated its virulence in an insect host, Galleria mellonella. In addition, our data suggests that this effect is mediated by mutations and epigenetic modifications of bacterial genes moderating the onset of the temperate phage's lytic cycle. Given the abundance of temperate phages in bacterial genomes (Canchaya et al., 2003), the sensitivity of the onset of their lytic cycle to environmental conditions (Howard-Varona et al., 2017), and the predominance of environmental change due to climate change, our results warrants attention as a cautionary example of the dangers of predicting environmental effects on species without considering complex biotic interactions.
\end{abstract}

Keywords: prophage, virulence, experimental evolution, opportunistic pathogen. 
Evolution in phage-bacteria-insect system

Understanding the consequences of environmental changes and fluctuations on biota

26 is of high priority at a time when environmental conditions are altered due to climate change (Chevin et al., 2010; Kristensen et al., 2018). Biological interactions between species have been suggested to be particularly sensitive to environmental changes (Walther, 2010). In biological communities, such perturbed interactions can lead to cascading effects affecting other species and even other trophic levels (Ripple et al., 2016).

Bacterial communities represent an environmentally sensitive system prone to cascading effects across thropic levels (Buck and Ripple, 2017). While bacteria are controlled by phages which are often sensitive to environmental cues (Canchaya et al., 2003; Howard-Varona et al., 2017), they themselves affect other trophic levels by contributing to biochemical cycles (Madigan et al., 2015) and by being pathogens of other species (Buck and Ripple, 2017). Their potential for having a strong leverage on trophic cascades is aided by the tight co-evolutionary connections between hosts and pathogens, and their rapid evolutionary responses which are due to massive population sizes and very short generation times common in microbial systems (Buck and Ripple, 2017; Kerr, 2012). Although trophic cascades are frequently caused by top-down predation, the role of parasites and pathogens is far less thoroughly investigated (Buck and Ripple, 2017). Especially little is known about the role of rapid evolutionary changes triggering trophic cascades. Here we report a novel result where (1) the lytic cycle of a naturally-occurring prophage was triggered by cold temperature, which (2) caused evolutionary changes in bacteria evolving under cold conditions. These changes (3) lowered the likelihood of prophage activation and (4) resulted in a decrease of bacterial virulence in an insect host. (5) Virulence and phage activity were associated with several genetic mutations and epigenetic modifications. brate species, but is also responsible for nosocomial infections in humans (Flyg et al., 52 1980; Grimont and Grimont, 2006). In-silico tools predicted the presence of seven 


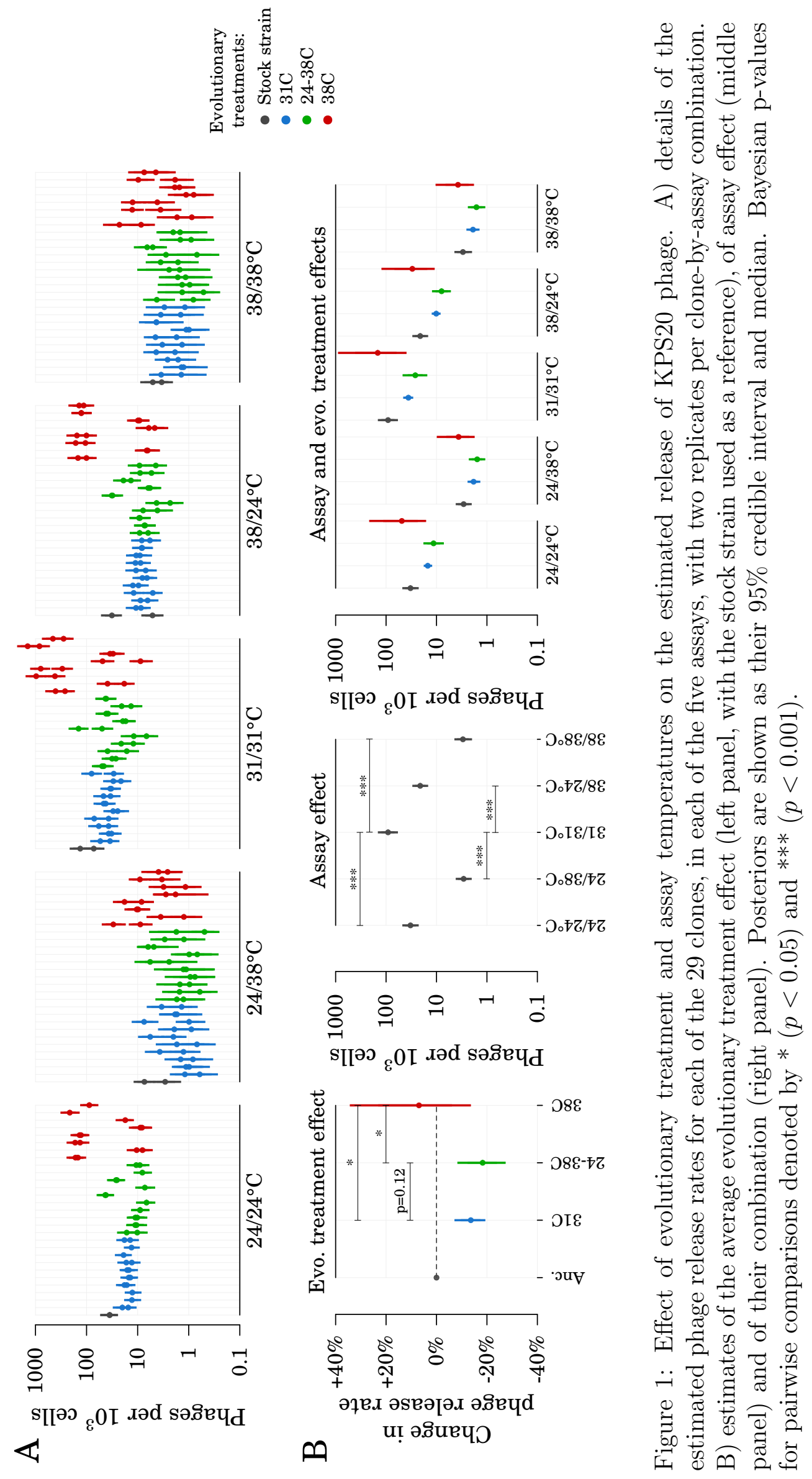


Evolution in phage-bacteria-insect system

prophages inside the genome of the $S$. marcescens stock strain sequenced in our study,

54 of which four were predicted to be incomplete prophages lacking some genes essential for phage production (Supplementary Figure S1, Supplementary Table S1). To explore

56 under which conditions those prophages could be activated, we designed and used a qPCR-based method to estimate the rate of induction of prophages by quantifying the extracellular phage sequences under various temperature assays. The only extracellular phage sequences detected by qPCR in the conditions of our assays showed significant

60 sequence similarity to Serratia phage KPS20 (Matsushita et al., 2009), and its release was more pronounced in the low- and medium- rather than high-temperature assays.

62 Such environmental sensitivity for prophage activation suggests that evolution at colder environments could potentially trigger counter-adaptations in bacteria to diminish their

64 fitness losses due to phages (Canchaya et al., 2003).

To test if environmental selection could affect phage activation, we used strains from 66 a previous evolution experiment where populations of $S$. marcescens evolved under either (i) constant hot temperature $\left(38^{\circ} \mathrm{C}\right)$, (ii) constant moderate temperature $\left(31^{\circ} \mathrm{C}\right)$ 68 or (iii) daily fluctuations between 24 and $38^{\circ} \mathrm{C}$ (with mean temperature of $31^{\circ} \mathrm{C}$ ) (Ketola et al. (2013) and Supplementary Figure S2). We isolated several independently

70 evolved clones from those evolutionary treatments $(\mathrm{n}=8,10$ and 10 , respectively) and investigated phage activation in these clones with two-day thermal assays. The

72 thermal assays were (daily temperatures given for first/second day) $24 / 24^{\circ} \mathrm{C}, 24 / 38^{\circ} \mathrm{C}$, $31 / 31^{\circ} \mathrm{C}, 38 / 24^{\circ} \mathrm{C}$ and $38 / 38^{\circ} \mathrm{C}$, thus enabling to test both the effect of mean temper-

74 ature and of temperature fluctuations on phage activation.

As hypothesized, we found evolutionary tempering of the prophage activation in 76 cooler environments: the strains evolved at $38^{\circ} \mathrm{C}$ released $23 \%$ more phages than strains evolved at $31^{\circ} \mathrm{C}$ and $31 \%$ more phages than strains evolved at $24-38^{\circ} \mathrm{C}$ (Figure 1B).

78 Mean patterns of KPS20 production did not differ significantly between strains that had evolved at lower mean temperature $\left(31^{\circ} \mathrm{C}\right.$ versus $\left.24-38^{\circ} \mathrm{C}\right)$. The main driver 80 of phage induction in our assays was experiencing a medium $\left(31^{\circ} \mathrm{C}\right)$ or cold $\left(24^{\circ} \mathrm{C}\right)$ 
Evolution in phage-bacteria-insect system

temperature over the last day of a given assay, rather than experiencing a temperature change between the two days: ending an assay at $31^{\circ} \mathrm{C}$ induced about three times more phages than ending an assay at $24^{\circ} \mathrm{C}$, and ending an assay at $24^{\circ} \mathrm{C}$ induced about ten times more phages than ending an assay at $38^{\circ} \mathrm{C}$. The consistency between higher phage activation rates at lower assay temperature and the selection of lower phage activation rates in clones evolved at those temperatures suggests that the presence of KPS20 prophage is having an effect on bacterial fitness, via phage release and cell lysis, especially at lower temperatures.

Bacterial virulence has been often linked both to bacterial density and to prophages 90 presence (Rutherford and Bassler, 2012; Nanda et al., 2015). To explore how environmentally triggered evolutionary changes in phage-bacteria interaction might cascade

92 to lower trophic levels (i.e. on hosts of bacteria), we conducted a virulence experiment using an insect host. Virulence of the experimentally evolved strains was estimated by measuring the survival time of waxmoth Galleria mellonella larvae injected with a small volume $(5 \mathrm{\mu l})$ of bacterial culture in two assay environments: $24^{\circ} \mathrm{C}$ and $31^{\circ} \mathrm{C}$.

96 We did not use $38^{\circ} \mathrm{C}$ as the high incubation temperature since waxmoth larvae cannot survive at this temperature. A Cox proportional hazards mixed model, controlling for the body mass of the larvae and the initial density of the bacterial sample (Figure 2A), revealed that average virulence of clones evolved at hot temperature $\left(38^{\circ} \mathrm{C}\right)$ tended

100 to be higher than for clones evolved at lower mean temperature when larvae were incubated at $24^{\circ} \mathrm{C}\left(38^{\circ} \mathrm{C}\right.$ versus $24-38^{\circ} \mathrm{C}, p=0.057$ (Bayesian $p$-value); $38^{\circ} \mathrm{C}$ versus $10231^{\circ} \mathrm{C}, p=0.066$ ) (Figure $2 \mathrm{~B}$ ). When larvae were incubated at $31^{\circ} \mathrm{C}$, this difference disappeared $\left(38^{\circ} \mathrm{C}\right.$ versus $24-38^{\circ} \mathrm{C}, p=0.11 ; 38^{\circ} \mathrm{C}$ versus $\left.31^{\circ} \mathrm{C}, p=0.34\right)$.

To confirm those tentative virulence results we utilized a much larger pool of evolved clones from the same original experiment Ketola et al. (2013), which confirmed that 106 clones evolved at $38^{\circ} \mathrm{C}$ had indeed a higher virulence than the others when assayed at room temperature $\left(p<0.01\right.$ for comparisons of $38^{\circ} \mathrm{C}$ clones with both $24-38^{\circ} \mathrm{C}$ 108 and $31^{\circ} \mathrm{C}$ clones, Supplementary Figure S4). This experiment also confirmed that the 

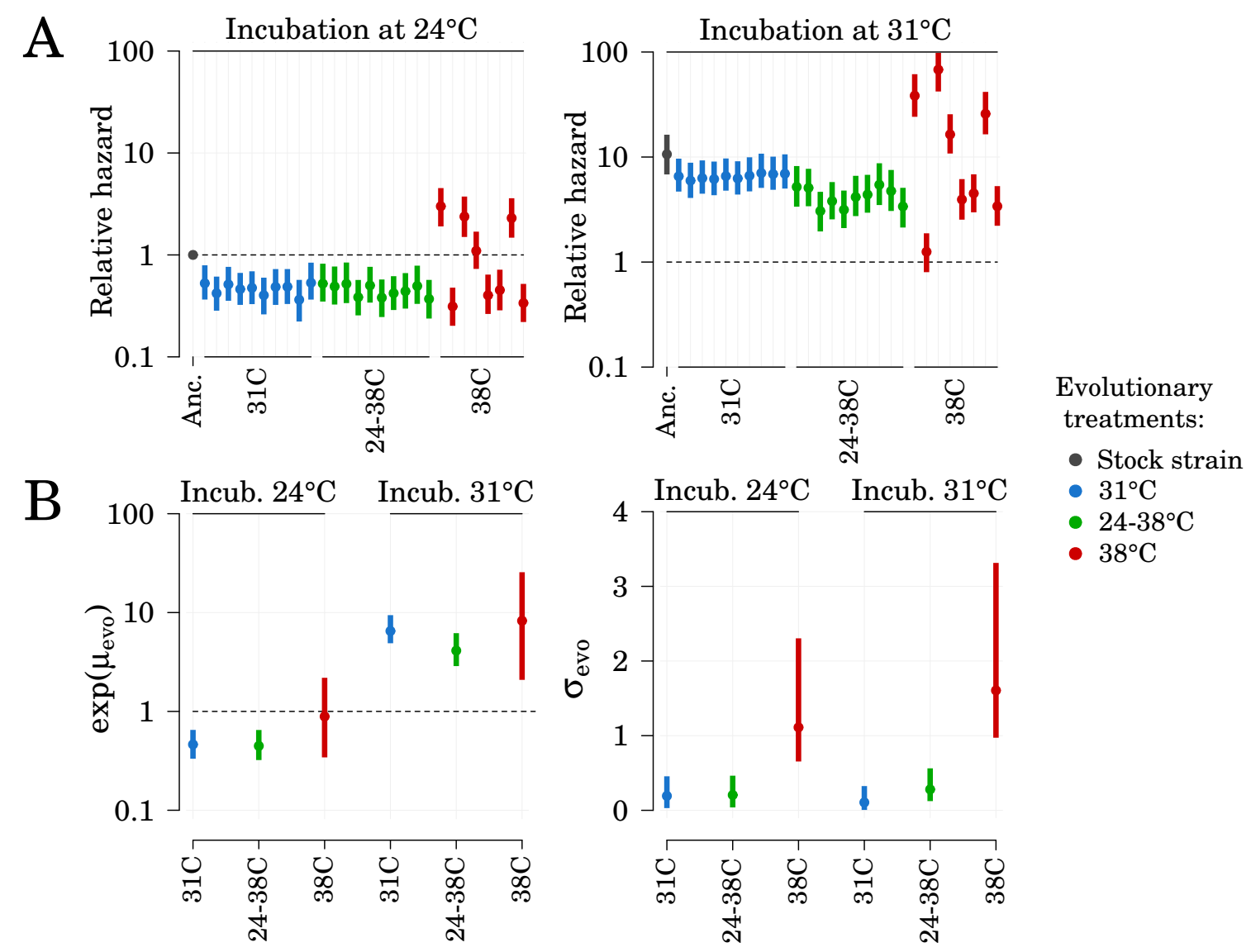

Figure 2: Effect of evolutionary treatment on strains virulence in waxmoth larvae at two incubation temperatures. A) relative hazards for individual strains. The relative hazards were estimated from a Bayesian implementation of a Cox proportional-hazards model and are corrected for the effects of injection batch, larval body mass and optical density of injected cultures. All relative hazards are relative to the hazard rate from the stock strain in incubation at $24^{\circ} \mathrm{C}$ (denoted by a broken horizontal line). B) Mean relative hazards per evolutionary treatment and per incubation temperature $\left(\exp \left(\mu_{\text {evo }}\right)\right)$ and standard deviation of the $\log$-relative hazards per evolutionary treatment and per incubation temperature $\left(\sigma_{\text {evo }}\right)$, as estimated by the model. For each variable, $95 \%$ credible interval and median of the posterior are shown. 
clones randomly chosen for sequencing were broadly representative of the larger pool 110 of clones isolated from the evolved populations.

When put in relation with the phage activation results, decreased virulence in the 112 insect host accompanied with decreased amount of virions when cultivated outside of the host suggests that phage production by the bacteria closely relates to its virulence

114 in the insect host. This was strongly supported by the correlation between average strain virulence in waxmoth larvae and average KSP20 activation rates (Spearman's $116 \rho=0.52, p=0.004)$.

Phage-encoded virulence factors are well-known mechanisms in bacterial virulence,

118 and are often considered one of the benefits explaining the maintenance of prophages in bacterial genome (Koskella and Brockhurst, 2014). However, none of the proteins

120 encoded by KSP20 did resemble any known virulence factors. Although this does not preclude that the proximal causal factor for virulence could be sequences of the

122 phage (Fortier and Sekulovic, 2013), it is also possible that endotoxins that are released normally from $S$. marcescens upon lysis can be causative agent in affecting virulence,

124 as Serratia marcescens lysates are known to be cytotoxic on their own (Petersen and Tisa, 2012), and phage lytic cycle releases them upon bacteria burst. Since none of the sequenced 28 evolved clones actually harbored genetic variation in the KSP20 prophage sequence, it can be reasonably expected that epigenetic modifications or mutations

128 occurring elsewhere in the genome must be responsible for differences in the likelihood of entering the lytic cycle.

Using whole-genome sequencing, we identified 54 variable loci across all evolved clones used in this study $(\mathrm{n}=28)$ compared to the stock strain (Figure 3 and Supplementary Tables S2 and S3). We investigated the association between genetic variants present in at least two strains and phenotypic traits using t-tests and adjustment of 134 p-values for false-discovery rate. Phenotypic traits included virulence and phage release but also previously measured traits such as growth rate and biomass yield in 136 several thermal conditions (referred to as temperature-related traits) and growth rate 




Figure 3: Alignment of the genomes from the 29 sequenced strains showing the genetically variable loci. Each circular track represents a sequenced genome, for which the evolutionary treatment is color-coded. Minor alleles for genetic variants are shown in light grey (SNP) and dark grey (indels). Marks on the outer part of the map indicates non-synonymous variants (non-synonymous SNPs and indels resulting in a frame shift). 

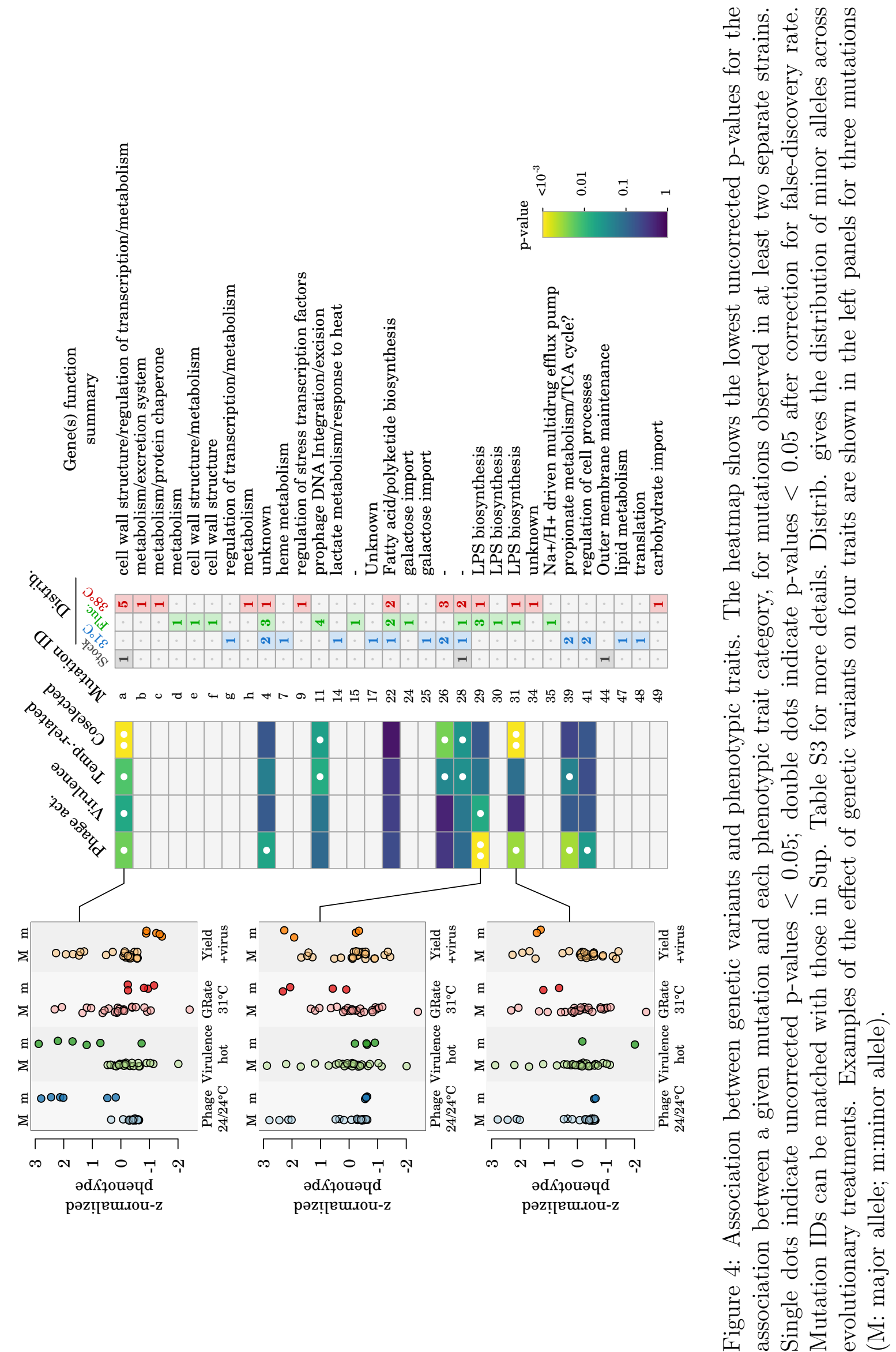
and biomass yield in the presence of predator, virus, or chemical DTT (referred to as coselected traits) (Ketola et al., 2013).

The variable loci most associated with phage release were a, 29, 31 and 39 (fdrcorrected p-values between 0.01 and 0.1 ) and those most associated with virulence in the insect host were $a, 11,28$ and 29 (fdr-corrected p-values between 0.01 and 0.1 )

142 (Figure 4$)$. These genetic variants were located in or close to $(<500 \mathrm{bp})$ genes annotated as transcriptional regulators (molybdenum-dependent transcriptional regulator and transcriptional regulator RcsB involved in motility and capsule and biofilm formation in E. coli) and enzymes involved in the cell wall and outer membrane structure 146 and biofilm formation (peptidoglycan synthase, two glycosyltransferases and a cellulose biosynthesis protein BcsG) (Figure 4, Supplementary Table S3). Those genes point to148 wards a potential role for modifications of biofilm structure and of the outer structure of the cellular envelope in modulating phage particle production and virulence in the

150 insect host. Some of those loci, in particular $a$ and 31, were also associated with the coselected traits (Figure 4), which emphasizes the pleiotropic effect of the genes in152 volved. Additionally, another striking pattern in the genetic variants pointing to the important role of the outer cellular envelope in the evolution experiment was the presence of three independent mutations located in a single glycosyltransferase gene and close to the putative active site of the protein (mutations 30, 31 and 32, Supplementary

156 Table S3). These mutations were observed independently in three strains evolved at $24-38^{\circ} \mathrm{C}$ and in one strain evolved at $38^{\circ} \mathrm{C}$. We also noted that haplotype $a$, compris158 ing eleven associated genetic loci, was shared by 5 out of the 8 strains evolved at $38^{\circ} \mathrm{C}$ and by the stock strain, but by none of the other sequenced strains. This points to the existence of some standing genetic variation at the onset of the experiment, which was then subjected to selection during the experimental evolution (Bruneaux et al., 2019) and subsequently taken into account in downstream analyses by using haplotype $a$ as a covariate.

164 In addition to nucleotide sequences, the data we obtained from the PacBio SMRT 
bioRxiv preprint doi: https://doi.org/10.1101/850248; this version posted November 21, 2019. The copyright holder for this preprint (which was not certified by peer review) is the author/funder, who has granted bioRxiv a license to display the preprint in perpetuity. It is made available under aCC-BY 4.0 International license.

\section{Evolution in phage-bacteria-insect system}

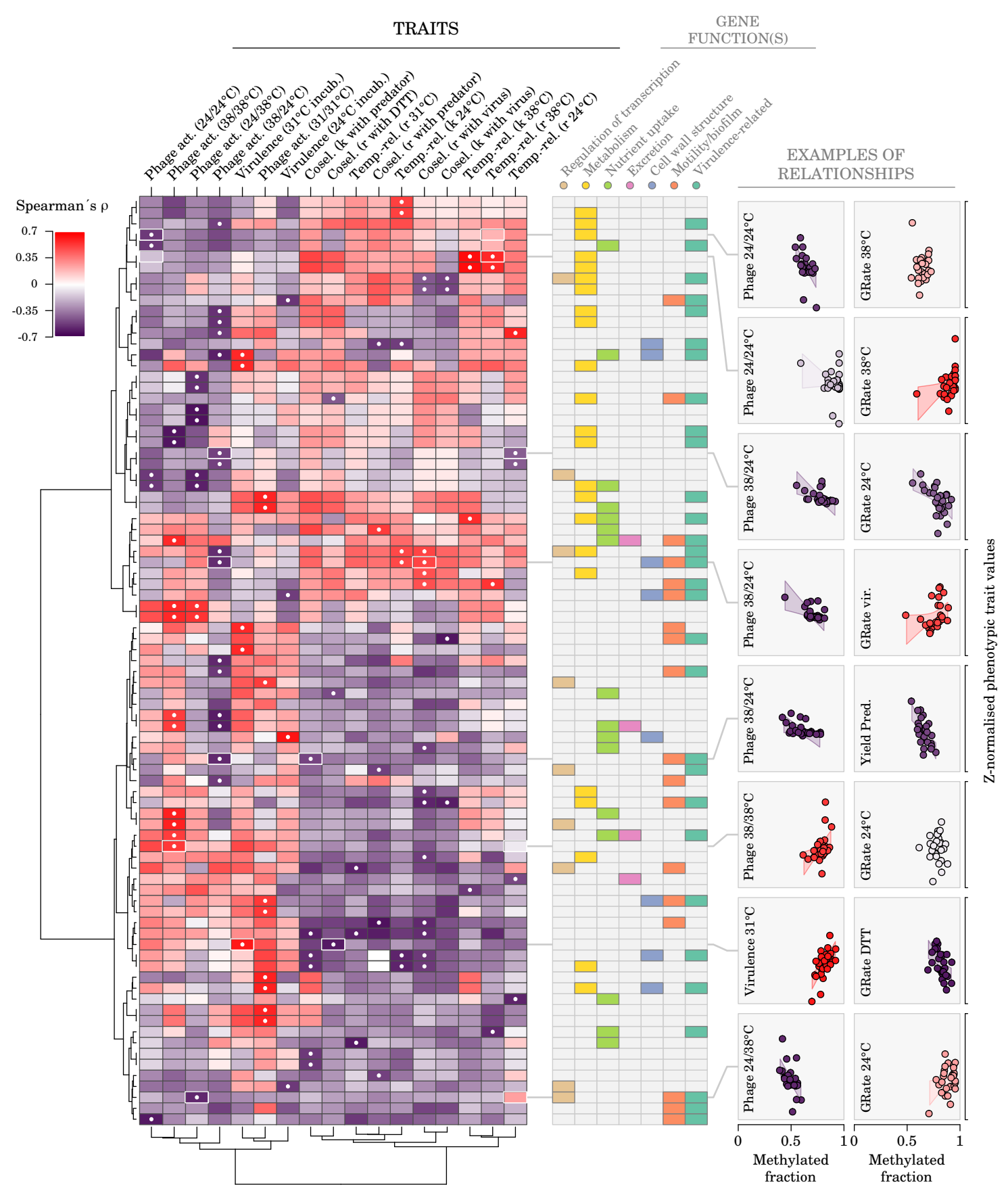

Figure 5: Association between epigenetic changes and phenotypic traits. The heatmap depicts the largest correlations between m6A methylation fractions associated with a given gene (rows) and phenotypes (columns). Only m6A from GATC motifs which were not fully methylated across sequenced strains and which were significantly associated with at least one trait are shown. A white dot indicates a significant association (uncorrected $p$-value $<0.005$ for Spearman's $\rho$ ). Probable gene functions are based on manual curation. A more detailed view of the genes associated with each trait is presented in Supplementary Tables S5-S11. 
Evolution in phage-bacteria-insect system

method also provided information about base methylation. In S. marcescens, adenosines present in GATC motifs are methylated into m6A by the Dam enzyme at a very high rate ( $>98 \%$ of GATC motifs were methylated on both strands in our dataset). The remaining GATC motifs can be either hemi-methylated or unmethylated. Adenosine methylation can influence gene expression by affecting the binding of regulatory 170 proteins to promoter regions of genes (Gomez-Gonzalez et al., 2019) or by affecting transcription speed via increased DNA stability of gene bodies (Riva et al., 2004a,b).

172 Such epigenetic regulation can be maintained across rounds of DNA replication by competitive binding to target DNA between the Dam responsible for methylation and 174 regulatory proteins specific to the same region (Casadesús and Low, 2006, 2013), and can thus be subject to selection.

Among GATC motifs which were not fully methylated in our dataset, and after taking into account the effect of haplotype $a$ on phenotypic traits in order to detect epigenetic effects independently from this major genetic component, we did not find association between evolutionary treatments and methylated fractions. However we did identify adenosines for which changes in methylation level were associated with phenotypic changes (Figure 5). For a given phenotypic trait, GATC loci exhibiting both positive and negative correlations between methylated fractions and the trait values could be observed (Figure 5, heatmap panel). Manual curation of the genes associated with GATC motifs related to phenotypic changes showed that many of them were involved in (1) transcription regulation, (2) cell metabolism, (3) nutrient capture and transport into the cell, (4) excretion into the outer medium, (5) cell envelope structure (including peptidoglycan and lipopolysaccharide biosynthesis) and (6) biofilm

188 formation, adherence or motility (Figure 5, gene functions panel and Supplementary Tables S5-S11). Many of those functional categories have been shown to be critical for 190 pathogen virulence in other bacterial species, in particular for nutrient capture in the challenging host medium (Ren et al., 2018; Liu et al., 2017), for recognition of the host

192 habitat via its nutrient signature (López-Garrido et al., 2015; Krypotou et al., 2019) 
Evolution in phage-bacteria-insect system

and for biofilm formation, adherence and motility which have a key role in colonization and successful invasion of the host tissues (Turner et al., 2009; Luo et al., 2017). The numerous candidate genes involved in lipopolysaccharide biosynthesis also suggest that the $\mathrm{O}$ antigen, which can classically be involved both in cell recognition by phages and in bacterial virulence in its host (Chart et al., 1989; Li and Wang, 2012), could act as

198 a major player of evolutionary trade-offs between bacterial virulence and resistance to phage infection.

The importance of the phage in shaping the genome, phenotype and selection is very evident in our study from the fact that none of the candidate genes is particu-

202 larly well connected with thermal selection pressures, which was the primary selective pressure imposed by the experiment used to generate those bacterial strains. For ex204 ample we did not find indication of involvement of HSP/DNAK genes in mutations or epigenetic modifications, that are known to be the target of selection in hot and

206 fluctuating environments (Sørensen et al., 2003; Ketola et al., 2004; Sørensen et al., 2016). In principle, stressful environments could select genes affecting acquisition of 208 resources, resource sparing and plasticity (Kristensen et al., 2018) in which changes in (1) transcription regulation, (2) cell metabolism and (3) nutrient capture and transport

210 into the cell could play a role, as seen in the clones sequenced in this study (Figure 5 and Supplementary Table S3).

212 The strong trophic cascade caused by evolutionary adaptation of bacteria to its phage, with consequences on virulence in insect host is a novel finding. As bacteria

214 have a strong impact on the biosphere and biochemical cycles, and furthermore act as important pathogens, the phages residing in most of the sequenced bacterial species 216 could indirectly play a major role in earth communities and in health (Abedon and LeJeune, 2005), for example through implications on microbiota in the gut or setting

218 the divide between life and death of their hosts via changes in virulence. Our results clearly show how biological interactions can predominate evolutionary changes, even 220 when imposed selection regimes are completely abiotic. Such a result warrants at- 
tention, as a cautionary example of the dangers of considering only single species in

222 isolation and ignoring complex biotic interactions when trying to predict range expansions and climate change influences on biota.

224 Acknowledgements. We acknowledge Kati Saarinen and Lauri Mikonranta for help with the virulence assays, the Academy of Finland (Project 278751) and the Centre of

226 Excellence in Biological Interactions for funding and facilities and the CSC - IT Center for Science, Finland, for computational resources used in this project. 


\section{Methods}

\section{Experimental evolution of bacterial populations}

230 To initiate the experiment a freshly isolated Serratia marcescens ancestor derived from the ATCC 13880 stock strain was grown overnight at $31^{\circ} \mathrm{C}$ in the low-nutrient medium

232 SPL 1\% (hay extract) (Ketola et al., 2013) to high density and spread to 30 populations (10 populations per thermal treatment). $400 \mu \mathrm{L}$ populations were placed under

234 constant $31^{\circ} \mathrm{C}$, constant $38^{\circ} \mathrm{C}$, or daily fluctuating $\left(24-38^{\circ} \mathrm{C}\right.$, mean $\left.31^{\circ} \mathrm{C}\right)$ thermal treatments. Resources (hay extract medium) were renewed daily for 30 days and after

236 the experiment clones were isolated from each of the populations by dilution plating samples to LB agar plates. Clones were grown overnight in hay extract to high den-

238 sity after which samples were frozen to 100-well Bioscreen plate and mixed 1:1 with $80 \%$ glycerol, in randomized order. One clone per population was randomly chosen for

240 sequencing. Two populations from the constant $38^{\circ} \mathrm{C}$ treatment were lost during the experimental evolution, resulting in 10 clones from constant $31^{\circ} \mathrm{C}, 8$ clones from con-

242 stant $38^{\circ} \mathrm{C}$ and 10 clones from fluctuating $24-38^{\circ} \mathrm{C}$ being sequenced (Supplementary Figure S2).

\section{DNA extraction and sequencing}

Selected clones $\left(\mathrm{n}=10,8\right.$ and 10 from $31^{\circ} \mathrm{C}, 38^{\circ} \mathrm{C}$ and fluctuating $24-38^{\circ} \mathrm{C}$ evolution-

246 ary treatments, respectively) were grown from a frozen stock (40\% glycerol) using a cryoreplicator into $400 \mu \mathrm{L}$ of SPL $1 \%$ overnight. A preculture of the stock strain was

248 also initiated from a frozen aliquot in a similar volume. $150 \mathrm{ml}$ of SPL 1\% were inoculated with these precultures the next day and grown for 24 hours. Cells were pelleted

250 and bacterial DNA was extracted using the Wizard Genomic DNA Purification Kit from Promega (WI, USA), following the instructions provided by the manufacturer.

252 Extracted DNA was resuspended in water and one DNA sample (20 to $60 \mu \mathrm{g}$ ) per clone was sequenced by the DNA Sequencing and Genomics Laboratory of the Univer- 
Evolution in phage-bacteria-insect system

sity of Helsinki on a PacBio RS II sequencing platform using P6-C4 chemistry, with two single-molecule real-time sequencing (SMRT) cells run per DNA sample. For each sample, reads were assembled with the PacBio RS_HGAP_Assembly.3 protocol. This assembly was processed with Gap4 to generate a first reference sequence. The PacBio RS_Resequencing. 1 protocol was subsequently run 2 to 3 times to map the reads to the reference sequence and generate a consensus sequence. Methylated bases and methylation motifs were detected using the PacBio RS_Modification and Motif_Analysis protocol which uses inter-pulse duration (IPD) ratios to identify modified bases. This

262 protocol labelled detected modified bases as m6A, m4C or "modified base" if the modification type could not be identified and estimated the fraction of modified copies for $\mathrm{m} 6 \mathrm{~A}$ and $\mathrm{m} 4 \mathrm{C}$ bases. Estimated fractions are robust for modifications generating a high IPD ratio like $\mathrm{m} 6 \mathrm{~A}$, but are more sensitive to coverage depth for modifications

266 with a lower IPD ratio like m4C (Clark et al., 2013). We used only estimated methylation fraction for m6A in our study.

\section{Genome annotation}

An annotated genome sequence is available for the reference strain corresponding to

270 the stock strain used in our study (ATCC 13880, RefSeq assembly accession number GCF000735445.1). We used Blast (Camacho et al., 2009) to align the contigs from this

272 reference assembly to the genome of our stock strain which differed only slightly from the sequence available in the database. After alignment, we propagated the predicted

274 CDS locations from the reference assembly to the genome of the stock strain.

We searched and downloaded from the UniProtKB database (https : //www . uniprot . org/ accessed on 2019-01-31) all the protein entries related to the species Serratia marcescens. We ran a tblastn search to match the predicted CDS from the stock strain

278 with those uniProtKB entries, keeping the hits with the highest bit scores. This resulted in 4356 out of 4543 CDS (95.9\%) of the stock sequence being assigned a UniProtKB

280 entry. Gene ontology annotations from the UniProtKB entries were propagated to the 
corresponding CDS of the stock strain genome. Additionally, we annotated CDS using the KEGG database by running blastKOALA (https://www.kegg.jp/blastkoala/).

\section{Detection of putative prophage sequences}

284 We used the PHAST (http://phast.wishartlab.com/) and the PHASTER (https: //phaster.ca/) in-silico tools to predict the presence of putative prophages in the sequenced stock strain genome (Zhou et al., 2011; Arndt et al., 2016). The submission to the tools servers was done on 2019-04-21. Seven putative prophages were detected

288 by PHAST, of which five were also detected by PHASTER (Supplementary Figure S1, Supplementary Table S1).

\section{Analysis of genetic variation}

The chromosome consensus sequences of the 29 strains were aligned using Mugsy 292 (Angiuoli and Salzberg, 2011). Variable loci were identified using a custom Python script to identify variable positions in the alignment and to extract allelic information

294 for each sequenced strain. To investigate the association between genetic variation and phenotypic traits, we ran one t-test per genetic variant and phenotypic trait com-

296 bination (using only genetic variants present in at least two strains). P-values were corrected for multiple testing using the false-discovery rate method (Benjamini and 298 Hochberg, 1995).

\section{Analysis of epigenetic variation}

300 Epigenetic data consisted of the methylation fraction for adenosine bases in all GATC motifs present in the stock strain genome (38150 GATC palindromes were present in

302 the stock strain genome, corresponding to 76300 adenosine bases for which methylation fraction values were analysed). Since the vast majority of the adenosines present 304 in GATC motifs were fully methylated in all sequenced strains, we first selected the 
subset of GATC motifs which exhibited low methylation level in at least one strain.

306 After applying our selection procedure (see Supplementary Methods for details), 483 palindromes corresponding to 966 adenosines (1.2\% of all the adenosines in GATC motifs) were kept for association analysis with phenotypes. Before testing for association between phenotypic traits and epigenetic data, we removed the effect of haplotype $a$ on phenotype by calculating for each trait the residuals from a linear model for the effect of the presence of haplotype $a$ on this trait. This conservative approach aimed

312 at detecting epigenetic loci associated with phenotypic traits independently from the effect of haplotype $a$, which was detected as a major genetic component in our experi-

314 ment. The significance of the association between each of these 966 epiloci and a given phenotypic trait was calculated as the $p$-value for Spearman's $\rho$ correlation cofficient between the phenotype values and the m6A methylation fractions for the 29 sequenced strains. We used Spearman's $\rho$ (i.e. rank correlation) to avoid excessive leverage from 318 extreme phenotypic values.

Epiloci were then associated with annotated genes: a gene was assigned to an epilocus if the adenosine base was located within the gene coding region, or less than 500 base pairs upstream of the initiation codon in order to cover potential regulatory regions of the gene. Several gene set approaches were then tested to try to detect biological functions or pathways related to the epiloci associated with phenotypic traits.

324 We used gene-ontology enrichment tests as implemented in the TopGO R package and KEGG pathway analysis with Wilcoxon rank-sum statistics to compare gene sets, but mostly only very general biological functions were detected with those approaches, such as amino acid or carbon metabolism, nutrient transport and translation (data not 328 shown). Since those approaches are targetting the detection of changes affecting a given biological function or pathway on average, but are not efficient to detect single genes 330 which might affect phenotype, we decided to generate lists of top candidate genes associated with each phenotypic trait (using uncorrected $p$-value $<0.005$ for Spearman's $332 \rho$ correlation as the threshold) and to manually curate those genes. Manual curation 
entailed a literature search to provide a brief description of the function of the gene product in bacterial species and to flag genes potentially involved in chosen categories of interest: regulation of transcription, metabolism, nutrient transport, excretion, cell wall structure, virulence and a larger last category embracing motility, biofilm formation, adherence and quorum sensing. Top candidate genes were then compared across 338 phenotypic traits.

\section{Quantification of phage induction using qPCR}

340 Induction rates of the seven candidate prophages (i.e. all prophage regions identified by PHAST, irrespective of the prediction for prophage completeness) were tested under

342 five temperature assay conditions. The assays lasted two days, and were made in SPL $1 \%$ under one of the following treatments: $31-31^{\circ} \mathrm{C}, 24-24{ }^{\circ} \mathrm{C}, 38-38^{\circ} \mathrm{C}, 24-38^{\circ} \mathrm{C}$ and

$34438-24^{\circ} \mathrm{C}$, where the temperatures are the temperatures on the first and second day, respectively, with a transfer to fresh medium between them (Supplementary Figure S5). The details of the induction quantification method are given in Appendix, but a brief description is given below.

348 We used seven specific primer pairs targetting each of the candidate prophage regions and one additional primer pair targetting a chromosomal, non-prophage-related bacterial gene (Supplementary Table S4) to quantify the amount of prophage DNA copies relative to the amount of bacterial genome copies present in a culture using

352 qPCR. The principle of our method is that an excess of prophage DNA copies would indicate prophage induction, as the transition to phage lytic life cycle results in repli354 cation of the phage genome, which is followed by assembly of phage progeny and ultimately the lysis of the host cell and the release of phage particles into the medium.

356 Given the low expected induction rates and the fact that qPCR estimates uncertainty is measured on a logarithmic scale, our approach to reliably quantify the excess of

358 prophage DNA, which might be attributable to prophage induction and released into phage particles, was the following (Supplementary Figure S5): (i) split each culture 
360 sample to be analysed into one raw sample and one supernatant sample obtained after gentle centrifugation to pellet bacteria cells, (ii) process both samples by DNase

362 to digest DNA fragments which were not protected inside a bacterial cell nor inside a phage particle, (iii) inactivate DNase and release DNA from cells and phage particles by

364 heating the samples at $95^{\circ} \mathrm{C}$ and (iv) quantify the amount of bacterial genome copies and of prophage DNA copies in both samples with qPCR. The supernatant sample is expected to be impoverished in bacterial cells, while phage particles can remain in suspension, and thus the proportion of prophage DNA copies which were not contained

368 in bacteria cells in the culture (i.e. which were presumably in phage particles) can be estimated from the differential decrease in qPCR estimates for prophage DNA copies and bacteria genome copies between the raw and supernatant samples (see the Appendix for details of the Bayesian model used to estimate phage-to-bacteria ratios and

372 the effects of assay and evolutionary treatments).

\section{Virulence experiment using waxmoth larvae}

374 We estimated the virulence of the experimental strains by measuring the longevity of waxmoth larvae (Galleria mellonella) injected with a small volume $(5 \mu \mathrm{l})$ of bac-

376 terial culture. Bacterial cultures of evolved strains were grown overnight at $31^{\circ} \mathrm{C}$ in Bioscreen wells in $400 \mu \mathrm{l}$ of SPL $1 \%$ inoculated with the strains frozen stocks using

378 a cryoreplicator. The stock strain was similarly grown overnight at $31^{\circ} \mathrm{C}$ in $8 \mathrm{ml}$ of SPL $1 \%$ in a loose-capped $15 \mathrm{ml}$ tube inoculated from a frozen sample. On injection

380 day, culture optical densities were measured and each larva was injected with 5 pl of a single culture in the hemocoel with a Hamilton syringe. For each strain, 20 larvae

382 were injected simultaneously; ten of those were then incubated at $24^{\circ} \mathrm{C}$ while the other ten were incubated at $31^{\circ} \mathrm{C}$. Larva survival was monitored at 1-3 hour intervals by

384 checking for larva movements, and time of death was recorded as the inspection time when a larva was found dead. Additionally, for each incubation temperature, ten larvae 386 were injected with sterile medium and ten with sterile water as controls. This setup 
was replicated four times, resulting in a total of 80 infected larvae per strain (40 to

388 incubation at $24^{\circ} \mathrm{C}$ and 40 to incubation at $31^{\circ} \mathrm{C}$ ). Due to some injection issues with a clogged syringe in the first replication block, data from only three replication blocks 390 were used for some strains.

We analysed the larva survival data using a Cox proportional hazards model, where 392 replication block, larval body mass, culture optical density, strain identity, incubation temperature and the interaction between strain identity and incubation temperature 394 were included as fixed effects. The model included the effect of strain evolutionary treatment on their virulence, using a hierarchical Bayesian approach in JAGS 4.1.0

396 (Plummer et al., 2003; Su and Yajima, 2015) with the R2jags package. The proportional harzards were implemented as described by Clayton (1991) based on code from

398 the OpenBUGS Examples (The OpenBUGS Project). The details of the model are presented in the Supplementary Methods. 
Evolution in phage-bacteria-insect system

\section{References}

Abedon, S. T. and LeJeune, J. T. Why Bacteriophage Encode Exotoxins and other Virulence Factors. Evolutionary Bioinformatics, 1:117693430500100001, January 2005. ISSN 1176-9343. doi: 10.1177/117693430500100001.

Angiuoli, S. V. and Salzberg, S. L. Mugsy: fast multiple alignment of closely related whole genomes. Bioinformatics, 27(3):334-342, February 2011. ISSN 1367-4803, 1460-2059. doi: 10.1093/bioinformatics/btq665.

Arndt, D., Grant, J. R., Marcu, A., Sajed, T., Pon, A., Liang, Y., and Wishart, D. S. PHASTER: a better, faster version of the PHAST phage search tool. Nucleic Acids Research, 44(W1):W16-W21, August 2016. ISSN 0305-1048, 1362-4962. doi: 10.1093/nar/gkw387.

Benjamini, Y. and Hochberg, Y. Controlling the False Discovery Rate: A Practical and Powerful Approach to Multiple Testing. Journal of the Royal Statistical Society. Series B (Methodological), 57(1):289-300, 1995. ISSN 0035-9246.

Bruneaux, M., Kronholm, I., Ashrafi, R., and Ketola, T. Roles of adenosine and cytosine methylation changes and genetic mutations in adaptation to different temperatures. submitted to BioRxiv, 2019.

Buck, J. C. and Ripple, W. J. Infectious Agents Trigger Trophic Cascades. Trends in Ecology \& Evolution, 32(9):681-694, September 2017. ISSN 0169-5347. doi: 10. 1016/j.tree.2017.06.009.

Camacho, C., Coulouris, G., Avagyan, V., Ma, N., Papadopoulos, J., Bealer, K., and Madden, T. L. BLAST+: architecture and applications. BMC Bioinformatics, 10 (1):421, December 2009. ISSN 1471-2105. doi: 10.1186/1471-2105-10-421.

Canchaya, C., Proux, C., Fournous, G., Bruttin, A., and Brüssow, H. Prophage Genomics. Microbiology and Molecular Biology Reviews, 67(2):238-276, June 2003. ISSN 1092-2172. doi: 10.1128/MMBR.67.2.238-276.2003.

Casadesús, J. and Low, D. A. Epigenetic Gene Regulation in the Bacterial World. Microbiology and Molecular Biology Reviews, 70(3):830-856, September 2006. ISSN 1092-2172, 1098-5557. doi: 10.1128/MMBR.00016-06.

Casadesús, J. and Low, D. A. Programmed Heterogeneity: Epigenetic Mechanisms in Bacteria. Journal of Biological Chemistry, 288(20):13929-13935, May 2013. ISSN 0021-9258, 1083-351X. doi: 10.1074/jbc.R113.472274.

Chart, H., Row, B., Threlfall, E. J., and Ward, L. R. Conversion of Salmonella enteritidis phage type 4 to phage type 7 involves loss of lipopolysaccharide with concomitant loss of virulence. FEMS Microbiology Letters, 60(1):37-40, July 1989. ISSN 0378-1097. doi: 10.1111/j.1574-6968.1989.tb03415.x.

436 Chevin, L.-M., Lande, R., and Mace, G. M. Adaptation, Plasticity, and Extinction in a Changing Environment: Towards a Predictive Theory. PLOS Biology, 8(4): e1000357, April 2010. ISSN 1545-7885. doi: 10.1371/journal.pbio.1000357. 
Clark, T. A., Lu, X., Luong, K., Dai, Q., Boitano, M., Turner, S. W., He, C., and Korlach, J. Enhanced 5-methylcytosine detection in single-molecule, real-time sequencing via Tet1 oxidation. BMC Biology, 11(1):4, January 2013. ISSN 1741-7007. doi: 10.1186/1741-7007-11-4.

Clayton, D. G. A Monte Carlo Method for Bayesian Inference in Frailty Models. Biometrics, 47(2):467-485, 1991. ISSN 0006-341X. doi: 10.2307/2532139.

Flyg, C., Kenne, K., and Boman, H. G. Insect pathogenic properties of Serratia marcescens: phage-resistant mutants with a decreased resistance to Cecropia immunity and a decreased virulence to Drosophila. Journal of General Microbiology, 120 (1):173-181, September 1980. ISSN 0022-1287. doi: 10.1099/00221287-120-1-173.

Fortier, L.-C. and Sekulovic, O. Importance of prophages to evolution and virulence of bacterial pathogens. Virulence, 4(5):354-365, July 2013. ISSN 2150-5608. doi: $10.4161 /$ viru.24498.

Gomez-Gonzalez, P. J., Andreu, N., Phelan, J. E., de Sessions, P. F., Glynn, J. R., Crampin, A. C., Campino, S., Butcher, P. D., Hibberd, M. L., and Clark, T. G. An integrated whole genome analysis of Mycobacterium tuberculosis reveals insights into relationship between its genome, transcriptome and methylome. Scientific Reports, 9(1):5204, March 2019. ISSN 2045-2322. doi: 10.1038/s41598-019-41692-2.

Grimont, F. and Grimont, P. A. D. The Genus Serratia. In Dworkin, M., Falkow, S., Rosenberg, E., Schleifer, K.-H., and Stackebrandt, E., editors, The Prokaryotes: Volume 6: Proteobacteria: Gamma Subclass, pages 219-244. Springer New York, New York, NY, 2006. ISBN 978-0-387-30746-6. doi: 10.1007/0-387-30746-X_11.

Howard-Varona, C., Hargreaves, K. R., Abedon, S. T., and Sullivan, M. B. Lysogeny in nature: mechanisms, impact and ecology of temperate phages. The ISME Journal, March 2017. ISSN 1751-7362. doi: 10.1038/ismej.2017.16.

Kerr, P. J. Myxomatosis in Australia and Europe: a model for emerging infectious diseases. Antiviral Research, 93(3):387-415, March 2012. ISSN 1872-9096. doi: 10.1016/j.antiviral.2012.01.009.

Ketola, T., Mikonranta, L., Zhang, J., Saarinen, K., Örmälä, A.-M., Friman, V.-P., Mappes, J., and Laakso, J. Fluctuating temperature leads to evolution of thermal generalism and preadaptation to novel environments. Evolution, 67:2936-2944, 2013.

Ketola, T., Laakso, J., Kaitala, V., and Airaksinen, S. Evolution of Hsp90 Expression in Tetrahymena Thermophila (protozoa, Ciliata) Populations Exposed to Thermally Variable Environments. Evolution, 58(4):741-748, 2004. ISSN 1558-5646. doi: 10. 1111/j.0014-3820.2004.tb00407.x.

474 Koskella, B. and Brockhurst, M. A. Bacteria-phage coevolution as a driver of ecological and evolutionary processes in microbial communities. Fems Microbiology Reviews, 38(5):916-931, September 2014. ISSN 0168-6445. doi: 10.1111/1574-6976.12072. 
Evolution in phage-bacteria-insect system

Kristensen, T. N., Ketola, T., and Kronholm, I. Adaptation to environmental stress at different timescales. Annals of the New York Academy of Sciences, 0(0), 2018. ISSN 1749-6632. doi: 10.1111/nyas.13974.

Krypotou, E., Scortti, M., Grundström, C., Oelker, M., Luisi, B. F., Sauer-Eriksson, A. E., and Vázquez-Boland, J. Control of Bacterial Virulence through the Peptide Signature of the Habitat. Cell Reports, 26(7):1815-1827.e5, February 2019. ISSN 2211-1247. doi: 10.1016/j.celrep.2019.01.073.

Li, J. and Wang, N. The gpsX gene encoding a glycosyltransferase is important for polysaccharide production and required for full virulence in Xanthomonas citri subsp. citri. BMC Microbiology, 12(1):31, March 2012. ISSN 1471-2180. doi: 10.1186/ 1471-2180-12-31.

Liu, W., Huang, L., Su, Y., Qin, Y., Zhao, L., and Yan, Q. Contributions of the oligopeptide permeases in multistep of Vibrio alginolyticus pathogenesis. MicrobiologyOpen, 6(5), July 2017. ISSN 2045-8827. doi: 10.1002/mbo3.511.

Luo, M., Yang, S., Li, X., Liu, P., Xue, J., Zhou, X., Su, K., Xu, X., Qing, Y., Qiu, J., and Li, Y. The KP1_4563 gene is regulated by the cAMP receptor protein and controls type 3 fimbrial function in Klebsiella pneumoniae NTUH-K2044. PLoS ONE, 12(7), July 2017. ISSN 1932-6203. doi: 10.1371/journal.pone.0180666.

López-Garrido, J., Puerta-Fernández, E., Cota, I., and Casadesús, J. Virulence Gene Regulation by l-Arabinose in Salmonella enterica. Genetics, 200(3):807-819, July 2015. ISSN 0016-6731. doi: 10.1534/genetics.115.178103.

Madigan, M. T., Brock, T. D., Martinko, J. M., Madigan, M. T., and Martinko, J. M. Brock biology of microorganisms. Pearson, Boston, 2015. ISBN 978-0-321-89739-8. OCLC: 1020076450.

Matsushita, K., Uchiyama, J., Kato, S.-i., Ujihara, T., Hoshiba, H., Sugihara, S., Muraoka, A., Wakiguchi, H., and Matsuzaki, S. Morphological and genetic analysis of three bacteriophages of Serratia marcescens isolated from environmental water. FEMS Microbiology Letters, 291(2):201-208, February 2009. ISSN 0378-1097, 15746968. doi: 10.1111/j.1574-6968.2008.01455.x.

Nanda, A. M., Thormann, K., and Frunzke, J. Impact of Spontaneous Prophage Induction on the Fitness of Bacterial Populations and Host-Microbe Interactions. Journal of Bacteriology, 197(3):410-419, February 2015. ISSN 0021-9193, 1098-5530. doi: 10.1128/JB.02230-14.

Petersen, L. M. and Tisa, L. S. Influence of Temperature on the Physiology and Virulence of the Insect Pathogen Serratia sp. Strain SCBI. Applied and Environmental Microbiology, 78(24):8840-8844, December 2012. ISSN 0099-2240, 1098-5336. doi: 10.1128/AEM.02580-12.

514 Plummer, M. et al. Jags: A program for analysis of bayesian graphical models using gibbs sampling. In Proceedings of the 3rd international workshop on distributed statistical computing, volume 124, page 10. Vienna, Austria., 2003. 
Ren, W., Rajendran, R., Zhao, Y., Tan, B., Wu, G., Bazer, F. W., Zhu, G., Peng, Y.,

Huang, X., Deng, J., and Yin, Y. Amino Acids As Mediators of Metabolic Cross Talk between Host and Pathogen. Frontiers in Immunology, 9, 2018. ISSN 1664-3224. doi: 10.3389/fimmu.2018.00319.

Ripple, W. J., Estes, J. A., Schmitz, O. J., Constant, V., Kaylor, M. J., Lenz, A., Motley, J. L., Self, K. E., Taylor, D. S., and Wolf, C. What is a Trophic Cascade? Trends in Ecology 65 Evolution, 31(11):842-849, November 2016. ISSN 0169-5347. doi: $10.1016 /$ j.tree.2016.08.010.

Riva, A., Delorme, M.-O., Chevalier, T., Guilhot, N., Hénaut, C., and Hénaut, A. Characterization of the GATC regulatory network in E. coli. BMC genomics, 5(1): 48, July 2004a. ISSN 1471-2164. doi: 10.1186/1471-2164-5-48.

Riva, A., Delorme, M.-O., Chevalier, T., Guilhot, N., Hénaut, C., and Hénaut, A. The difficult interpretation of transcriptome data: the case of the GATC regulatory network. Computational Biology and Chemistry, 28(2):109-118, April 2004b. ISSN 1476-9271. doi: 10.1016/j.compbiolchem.2003.12.004.

Rutherford, S. T. and Bassler, B. L. Bacterial quorum sensing: its role in virulence and possibilities for its control. Cold Spring Harbor Perspectives in Medicine, 2(11), November 2012. ISSN 2157-1422. doi: 10.1101/cshperspect.a012427.

Su, Y.-S. and Yajima, M. R2jags: Using $R$ to Run 'JAGS', 2015. R package version $0.5-7$.

Sørensen, J. G., Kristensen, T. N., and Loeschcke, V. The evolutionary and ecological role of heat shock proteins. Ecology Letters, 6(11):1025-1037, 2003. ISSN 1461-0248. doi: $10.1046 /$ j.1461-0248.2003.00528.x.

Sørensen, J. G., Schou, M. F., Kristensen, T. N., and Loeschcke, V. Thermal fluctuations affect the transcriptome through mechanisms independent of average temperature. Scientific Reports, 6:30975, August 2016. ISSN 2045-2322. doi: $10.1038 /$ srep30975.

The OpenBUGS Project. Leuk: survival analysis using Cox regression.

Turner, K. H., Vallet-Gely, I., and Dove, S. L. Epigenetic Control of Virulence Gene Expression in Pseudomonas aeruginosa by a LysR-Type Transcription Regulator. PLoS Genetics, 5(12):e1000779, December 2009. ISSN 1553-7404. doi: 10.1371/ journal.pgen.1000779.

Walther, G.-R. Community and ecosystem responses to recent climate change. Philosophical Transactions of the Royal Society B: Biological Sciences, 365(1549):20192024, July 2010. doi: 10.1098/rstb.2010.0021.

Zarnetske, P. L., Skelly, D. K., and Urban, M. C. Biotic Multipliers of Climate Change. Science, 336(6088):1516-1518, June 2012. ISSN 0036-8075, 1095-9203. doi: 10.1126/ science.1222732. 

available under aCC-BY 4.0 International license.

Zhou, Y., Liang, Y., Lynch, K. H., Dennis, J. J., and Wishart, D. S. PHAST: a fast 556 phage search tool. Nucleic Acids Research, 39(Web Server issue):W347-352, July 2011. ISSN 1362-4962. doi: 10.1093/nar/gkr485. 


\section{Appendix}

\section{Supplementary Methods}

\section{Quantification of phage induction using qPCR}

(See also Supplementary Figure S5.)

562 Culture conditions for the temperature assays Frozen stocks had been stored at $-80{ }^{\circ} \mathrm{C}$ in $40 \%$ glycerol, with evolved clones stored in 100-well plates (Bioscreen

564 measurement plates), in randomized order and stock clone stored in microcentrifuge tubes. A preculture step in $400 \mathrm{\mu l}$ of SPL $1 \%$ at $31{ }^{\circ} \mathrm{C}$ was performed by using a

566 cryo-replicator to inoculate evolved clones into a new 100-well plate and by inoculating the stock strain into wells of another plate. After 24 hours, five identical 100-well

568 assay plates containing both the 28 evolved clones of interest and the stock clone were prepared by transferring $40 \mu \mathrm{l}$ of each preculture into $360 \mu \mathrm{l}$ of fresh SPL $1 \%$

570 ( 1 well per clone, i.e. 29 wells occupied per plate). For the first day of assay, one plate was incubated at $31^{\circ} \mathrm{C}$, two plates at $24^{\circ} \mathrm{C}$ and two plates at $38^{\circ} \mathrm{C}$. After

57224 hours, clones within a given plate were transferred to 29 previously empty new wells in the same plate $(40 \mu \mathrm{l}$ culture into $360 \mu \mathrm{l}$ fresh medium). For the second day

574 of assay, the plate from $31^{\circ} \mathrm{C}$ was kept at $31^{\circ} \mathrm{C}$, one plate from $24^{\circ} \mathrm{C}$ was kept at $24^{\circ} \mathrm{C}$ and the other was transferred to $38^{\circ} \mathrm{C}$, and one plate from $38^{\circ} \mathrm{C}$ was kept at

$57638^{\circ} \mathrm{C}$ while the other was transferred to $38^{\circ} \mathrm{C}$. After 24 hours, plates were taken for sample processing. Extra wells containing sterile SPL $1 \%$ medium were used on the

578 assay plates to monitor potential contamination during plate handling (which was not observed). The whole experiment was performed twice, starting with the same frozen

580 stocks but with independent precultures.

Sample processing and qPCR runs At the end of the second day of assay, each 582 of the 29 cultures in each of the 5 assay plates was processed in the following way: $50 \mathrm{\mu l}$ of native culture sample was transferred to a 96-well PCR plate, while the rest of

584 the culture was placed into a microcentrifuge tube, centrifuged at $13500 \mathrm{~g}$ for $5 \mathrm{~min}$ and $50 \mathrm{\mu l}$ of supernatant was transferred in the 96 -well plate, resulting in two paired

586 samples per culture (native and supernatant). Samples from a given assay plate were placed into the same 96-well plate. A DNase treatment was then performed to digest

588 DNA fragments which were not protected inside a bacteria cell or a phage particle. $5 \mu \mathrm{l}$ of DNase I at $0.1 \mathrm{mg} \mathrm{ml}^{-1}$ were added to each sample, followed by an incubation

590 at $37^{\circ} \mathrm{C}$ for $30 \mathrm{~min}$. DNA was then released from bacteria cells and potential phage particles by incubating the samples at $95^{\circ} \mathrm{C}$ for $30 \mathrm{~min}$ after having added $5 \mu \mathrm{l}$ of EGTA

592 (20 mM, pH 8) in order to hinder DNase I activity. The sample plates were then stored at $-20{ }^{\circ} \mathrm{C}$ until DNA quantification by qPCR runs.

594 Quantification of DNA target sequences was performed using prophage-specific primer pairs and one bacterial-gene-specific primer pair (Supplementary Table S4).

596 Preliminary experiments using the stock strain at $31^{\circ} \mathrm{C}$ having showed no detectable extra-cellular DNA at least for prophages 2 and 5, six qPCR were runs per 96-well

598 sample plate from this experiment using primers for prophages 1, 3, 4, 6, 7 and for bacterial gene purA2. Runs were performed using CFX Real Time PCR detection 
600 system (Bio-Rad laboratories, USA). Amplifications were performed in a final volume of $10 \mu l$, containing $5 \mu \mathrm{l}$ of $2 \mathrm{x}$ IQ SYBR Green Supermix (Bio-Rad), $0.5 \mu \mathrm{l}$ of forward

602 and reverse primers $(6 \mu \mathrm{M}$ each) and $1 \mu \mathrm{l}$ of undiluted sample. Amplifications for each primer pair were performed on separate qPCR plates, with in-plate calibration samples

604 for each run. Calibration samples were prepared by serial dilution of a stock solution of purified Serratia marcescens DNA of known concentration, and ranged in concen-

606 tration from $10^{6}$ to 1 genome copy per qPCR well, based on the predicted molecular weight of $S$. marcescens chromosome. Experimental and calibration samples were run

608 in triplicates within each qPCR plate. The qPCR reaction used an initial denaturation step lasting 3 min at $95^{\circ} \mathrm{C}$, followed by 41 cycles consisting of denaturation at $95^{\circ} \mathrm{C}$ for

$61010 \mathrm{~s}$, annealing at $61^{\circ} \mathrm{C}$ (for all prophage primers) or $56^{\circ} \mathrm{C}$ (for bacterial gene primers) for $10 \mathrm{~s}$, and elongation at $72^{\circ} \mathrm{C}$ for $30 \mathrm{~s}$. A melt curve analysis was performed at the

612 end of the run to check the quality of the amplified product (from $65^{\circ} \mathrm{C}$ to $95^{\circ} \mathrm{C}$, using increments of $0.5^{\circ} \mathrm{C}$ and $5 \mathrm{~s}$ steps). In-plate calibration samples were used to estimate

614 the efficiency $E$ of the qPCR reaction with the formula $E=-1+10^{(-1 / \text { slope })}$ where slope is the slope of the linear relationship between $C q$ values and $\log _{10}$ (concentration) for

616 the calibration samples. To test for an effect of potentially undegraded RNA molecules on phage activation estimates, some samples were incubated with RNase for 30min

618 just prior to qPCR runs. Estimates of phage activation for those samples were similar whether the samples were treated or untreated with RNase prior to qPCR runs, hence

620 data from both RNase-treated and untreated qPCR runs was used for downstream analysis.

622 Estimation of prophage induction rates and treatment effects using a Bayesian model We incorporated into a single Bayesian model the simultaneous estimation of

624 phage induction rates and of the effects of assay temperature and evolutionary treatment. To simplify its presentation here, we will first explain the modelling part related

626 to the estimation of induction rates for each culture well, based on the Cq values for the native and supernatant samples obtained from qPCR runs with bacterial and prophage 628 primers, before explaining the incorporation of assay and evolutionary treatment effects.

Let $c_{\text {bact,nat }}$ be the number of bacterial chromosome copies present in a native sample. The value of $c_{\text {bact,nat }}$ is determined from the qPCR run using the bacterial-genespecific purA2 primers. Let $c_{\text {pro,nat }}$ be the number of prophage DNA copies present in the native sample for e.g. prophage KSP20. The value of $c_{\text {pro,nat }}$ is determined from the $\mathrm{qPCR}$ run using the prophage-specific primers. Let's assume that this prophage is induced into phage particles at an activation rate $a$, such that the number of phage particles present in the native sample $c_{p h g, n a t}$ is related to the number of bacteria cells (i.e. the number of bacteria chromosome copies) by $c_{p h g, n a t}=a \times c_{\text {bact,nat }}$. Since the prophage primers can target the prophage sequence both in the bacterial genome and 
in phage particles, we have:

$$
\begin{aligned}
& c_{\text {pro,nat }}=c_{\text {bact }, \text { nat }}+c_{\text {phg,nat }} \\
& c_{\text {pro,nat }}=c_{\text {bact }, \text { nat }}+a \times c_{\text {bact }, \text { nat }} \\
& c_{\text {pro,nat }}=(1+a) \times c_{\text {bact }, \text { nat }}
\end{aligned}
$$

After centrifugation, we assume most bacteria cells have been pelleted and most phage particles (if any) have remained in suspension. Let $k$ be the concentration factor during centrifugation for this culture $(k \leq 1)$, so that $k=\frac{c_{b a c t, \text { sup }}}{c_{\text {bact,nat }}}$ where $c_{\text {bact,sup }}$ is the number of bacterial chromosome copies present in the supernatant samples, as determined by qPCR with purA2 primers. If $c_{\text {pro,sup }}$ is the number of prophage DNA copies in the supernatant sample determined by qPCR with the prophage primers and $c_{p h g, s u p}$ is the number of phage particles in the supernatant sample, and if we assume $c_{p h g, s u p}=c_{p h g, n a t}$ (i.e. we assume that the amount of phage particles pelleted during centrifugation is negligible), we have:

$$
\begin{aligned}
& c_{\text {pro,sup }}=c_{\text {bact,sup }}+c_{\text {phg }, \text { sup }} \\
& c_{\text {pro,sup }}=k \times c_{\text {bact }, \text { nat }}+c_{\text {phg }, \text { nat }} \\
& c_{\text {pro,sup }}=k \times c_{\text {bact,nat }}+a \times c_{\text {bact }, \text { nat }} \\
& c_{\text {pro,sup }}=(k+a) \times c_{\text {bact }, \text { nat }}
\end{aligned}
$$

Thus, to summarize, the two fundamental equations that relate the four qPCR measurements for a given culture $\left(c_{\text {bact,nat }} / c_{\text {bact,sup }} / c_{\text {pro,nat }} / c_{\text {pro,sup }}\right)$ and the prophage activation rate $a$ in this culture and that are used in the Bayesian model are:

$$
\begin{aligned}
c_{\text {pro,nat }} & =(1+a) \times c_{\text {bact }, \text { nat }} \\
c_{\text {pro,sup }} & =\left(\frac{c_{\text {bact }, \text { sup }}}{c_{\text {bact }, \text { nat }}}+a\right) \times c_{\text {bact }, \text { nat }}
\end{aligned}
$$

The priors and the deterministic relations of the statistical model are:

$$
\begin{aligned}
\forall i \in\left\{1 \ldots n_{\text {runs }}\right\}, \quad \alpha_{i} & \sim \operatorname{normal}(\mu=40, \sigma=10) \\
\beta_{i} & \sim \operatorname{normal}(\mu=3.5, \sigma=2) \\
\sigma_{C q} & \sim \operatorname{half-Cauchy}(\text { scale }=2.5)
\end{aligned}
$$

for the parameters of the $\mathrm{qPCR}$ calibration curve for each run (note that $\sigma_{C q}$ is shared 
across all qPCR runs) and:

$$
\forall i \in\left\{1 \ldots n_{\text {cultures }}\right\}, \quad \begin{aligned}
\log _{10}\left(c_{\text {bact }, \text { nat }, i}\right) & \sim \text { uniform }(0,20) \\
\log _{10}\left(k_{i}\right) & \sim \operatorname{half-Cauchy}(\text { scale }=2) \\
\log _{10}\left(a_{i}\right)+4 & \sim \operatorname{gamma}(\mu=2, \sigma=2) \\
\log _{10}\left(c_{\text {bact }, \text { sup }, i}\right) & =\log _{10}\left(k_{i}\right)+\log _{10}\left(c_{\text {bact }, \text { nat }, i}\right) \\
\log _{10}\left(c_{\text {pro, nat }, i}\right) & =\log _{10}\left(1+a_{i}\right)+\log _{10}\left(c_{\text {bact }, \text { nat }, i}\right) \\
\log _{10}\left(c_{\text {pro }, \text { sup }, i}\right) & =\log _{10}\left(k_{i}+a_{i}\right)+\log _{10}\left(c_{\text {bact }, \text { nat }, i}\right)
\end{aligned}
$$

630 for the characteristics of a given culture well. Note that here, we assume that the minimum value of activation rate $a$ is $10^{-4}$, which is approximatively the lower sensitivity threshold predicted for our method when we assume that $C q$ values are measured with a standard deviation $\sigma_{C q} \approx 0.48$ (Supplementary Figure S6). We model this as $634\left(\log _{10}\left(a_{i}\right)+4\right)$ following a Gamma distribution. In this explanation, we use fixed values for the parameters of the Gamma distribution, but when we will introduce the effect of assay and evolutionary treatment the $\mu$ and $\sigma$ parameters of this Gamma distribution will depend on the treatments.

The likelihood of the model due to calibration samples, for which the concentration values $\mathrm{cal}_{i}$ are known and the $\mathrm{Cq}$ values $\mathrm{Cq}_{i}^{\text {cal }}$ are observed, is (with $n_{\text {cal }}$ the number of qPCR wells with a calibration sample):

$$
\begin{aligned}
\forall i \in\left\{1 \ldots n_{\text {cal }}\right\}, \quad c_{i}^{\text {well }} & \sim \operatorname{Poisson}\left(\text { cal }_{i}\right) \\
\mathrm{Cq}_{i}^{\text {pred }} & =\alpha_{\text {run }_{i}}+\beta_{\text {run }} \times \log _{10}\left(c_{i}^{\text {well }}\right) \\
\mathrm{Cq}_{i}^{\text {cal }} & \sim \operatorname{normal}\left(\mu=\mathrm{Cq}_{i}^{\text {pred }}, \sigma=\sigma_{\mathrm{Cq}}\right)
\end{aligned}
$$

where run $_{i}$ is the index of the qPCR run. For qPCR wells containing samples of unknown concentration prepared from the culture wells in the assay plates, we set (with $n_{\text {unkn }}$ the number of qPCR wells with unknown samples and cult $_{i}$ the index of the original culture for each unknown sample):

$$
\forall i \in\left\{1 \ldots n_{\text {unkn }}\right\}, \quad \text { unkn }_{i}=\left\{\begin{array}{cc}
c_{\text {bact }, \text { nat }, \text { cult }} & \text { or } \\
c_{\text {bact }, \text { sup }, \text { cult }_{i}} & \text { or } \\
c_{\text {pro, nat }, \text { cult }_{i}} & \text { or } \\
c_{\text {pro,sup }, \text { cult }_{i}} &
\end{array}\right.
$$

depending on whether the unknown sample is run with purA2 $\left(c_{b a c t, . . .}\right)$ or prophage $\left(c_{\text {pro,... }}\right)$ primers and whether it is native $\left(c_{., \text {nat.. }}\right)$ or from supernatant $\left(c_{., \text {sup,. }}\right)$. The likelihood due to unknown samples is then of the same form as for the calibration 
samples:

$$
\begin{aligned}
\forall i \in\left\{1 \ldots n_{\text {unkn }}\right\}, \quad c_{i}^{\text {well }} & \sim \operatorname{Poisson}\left(\text { unkn }_{i}\right) \\
\mathrm{Cq}_{i}^{\text {pred }} & =\alpha_{\text {run }}+\beta_{\text {run }} \times \log _{10}\left(c_{i}^{\text {well }}\right) \\
\mathrm{Cq}_{i}^{\text {cal }} & \sim \operatorname{normal}\left(\mu=\mathrm{Cq}_{i}^{\text {pred }}, \sigma=\sigma_{\mathrm{Cq}}\right)
\end{aligned}
$$

This model formulation is sufficient to obtain posterior distributions for $\log _{10}\left(a_{i}\right)$ for each culture well $i$ in the assay plates. To model the effect of assay and evolutionary treatment, we extend the model by modifying the parameters of the previous prior for $a_{i}$ :

$$
\log _{10}\left(a_{i}\right)+4 \sim \operatorname{gamma}(\mu=2, \sigma=2)
$$

by:

$$
\begin{aligned}
& \forall i \in\left\{1 \ldots n_{\text {cultures }}\right\}, \quad \log _{10}\left(a_{i}\right)+4 \sim \operatorname{gamma}\left(\mu=\mu_{i}, \sigma=\sigma_{i}\right) \\
& \mu_{i} \sim \exp \left(\beta_{\text {assay }}\left[\text { assay }_{i}\right]+\beta_{\text {str }}\left[\text { str }_{i}\right]\right) \\
& \sigma_{i}=\sigma_{\text {assay }}\left[\text { assay }_{i}\right]
\end{aligned}
$$

where $a_{s s a y_{i}}$ is the index of the assay treatment for culture $i\left(1 \leq\right.$ assay $\left._{i} \leq 5\right)$ and $s t r_{i}$ is the index of the strain ID for culture $i\left(1 \leq s t r_{i} \leq 29\right)$. The priors for the effect of assay treatments are:

$$
\begin{aligned}
\text { Intercept: } & & \beta_{\text {assay }}[1] & =1 \\
\forall i \in\{2 \ldots 5\}, & & \beta_{\text {assay }}[i] & \sim \operatorname{normal}(\mu=0, \sigma=4) \\
\forall i \in\{1 \ldots 5\}, & & \sigma_{\text {assay }}[i] & \sim \operatorname{uniform}(0,10)
\end{aligned}
$$

The strain effects include a hierarchical effect of the evolutionary treatment (four levels: three evolution environments plus the stock strain). The priors for the strain and evolutionary treatment effects are:

$$
\begin{array}{rlrl}
\forall i \in\{1 \ldots 29\}, & & \beta_{\text {str }}[i] & \sim \operatorname{normal}\left(\mu=\mu_{\text {evo }}\left[\text { evo }_{i}\right], \sigma=\sigma_{\text {evo }}\left[\text { evo }_{i}\right]\right) \\
\forall i \in\{1 \ldots 4\}, & & \mu_{\text {evo }}[i] \sim \operatorname{normal}(\mu=0, \sigma=4) \\
& \sigma_{\text {evo }}[i] \sim \operatorname{uniform}(0,10)
\end{array}
$$

638 where $e v o_{i}$ is the index of the evolutionary treatment for strain $i$.

\section{Bayesian implementation of the Cox proportional hazards mixed model}

640 The virulence experiment dataset contained observations for $N=2182$ individual larvae. For each larvae $i$, survival time $s_{i}$ was calculated as the difference between recorded death time and injection time. The survival timeline for all larvae was divided into $T=20$ intervals, so that the $s_{i, i \in\{1 \ldots N\}}$ values were homogeneously distributed 
644 across intervals (i.e. all intervals contained approximatively the same number of death events). Intervals were defined by their boundaries $t_{j, j \in\{1 \ldots T+1\}}$, such that interval $j$ is $646\left[t_{j}, t_{j+1}\right)$ and is of duration $d t_{j}=t_{j+1}-t_{j}$.

The survival data was transformed into a risk variable $Y_{i}(j)$ and an event count variable $d N_{i}(j)$ defined for all $i \in\{1 \ldots N\}$ and $j \in\{1 \ldots T\}$ by:

$$
Y_{i}(j)=\left\{\begin{array}{ll}
1 & \text { if } s_{i}>t_{j} \\
0 & \text { otherwise }
\end{array} \text { and } d N_{i}(j)= \begin{cases}1 & \text { if } s_{i} \in\left[t_{j}, t_{j+1}\right) \\
0 & \text { otherwise }\end{cases}\right.
$$

The model assumes:

$$
d N_{i}(j) \sim \operatorname{Poisson}\left(Y_{i}(j) \times d \lambda_{0}(j) \times \exp \left(\beta z_{i}\right) \times d t_{j}\right)
$$

where $d \lambda_{0}(j)$ is the increment in the integrated baseline hazard from $t_{j}$ to $t_{j+1}$ and $\beta z_{i}$ is the product of the model parameters and of the covariate values for larva $i$. The term $\beta z_{i}$ corresponds to:

$$
\begin{aligned}
\beta z_{i}= & \beta_{b l k}\left[b l k_{i}\right]+\beta_{B M} B M_{i}+\beta_{O D} O D_{i}+\beta_{\text {str|incub } 24}\left[s t r_{i}\right] \times\left(1-i n c u b_{i}\right) \\
& +\beta_{\text {str } \mid \text { incub31 }}\left[s t r_{i}\right] \times \text { incub }_{i}
\end{aligned}
$$

where $b l k_{i}, B M_{i}, O D_{i}, s t r_{i}$, and $i n c u b_{i}$ are respectively the replication block, body mass, preculture OD, injected strain ID $\left(s t r_{i} \in\{1 \ldots 29\}\right)$ and incubation temperature (0 for $24^{\circ} \mathrm{C}, 1$ for $31^{\circ} \mathrm{C}$ ) for larva $i$. Square brackets indicate indexing of a vector parameter; $\beta_{b l k}$ is a vector containing the replication block effects and $\beta_{\text {str|incub24 }}$ and $\beta_{\text {str|incub31 }}$ are vectors containing the strain effects in the $24^{\circ} \mathrm{C}$ and $31^{\circ} \mathrm{C}$ incubations, respectively. To model the effect of the evolutionary treatment, we set, for $k \in\{1 \ldots 29\}$ :

$$
\begin{aligned}
& \beta_{\text {str } \mid \text { incub } 24}[k] \sim \operatorname{normal}\left(\mu_{\text {incub } 24}[\operatorname{evo}[k]], \sigma_{\text {incub } 24}[\operatorname{evo}[k]]\right) \\
& \beta_{\text {str } \mid \text { incub } 31}[k] \sim \operatorname{normal}\left(\mu_{\text {incub31 }}[\text { evo }[k]], \sigma_{\text {incub } 31}[\operatorname{evo}[k]]\right)
\end{aligned}
$$

where the vector evo allows to map the strain ID and one of the four evolutionary treatments (three different temperature regimes plus stock strain).

The priors we used were:

$$
\begin{aligned}
\beta_{b l k}[.] & \sim \operatorname{normal}(\text { mean }=0, \mathrm{sd}=10) \\
\beta_{B M} & \sim \operatorname{normal}(0,10) \\
\beta_{O D} & \sim \operatorname{normal}(0,10) \\
\mu_{\text {incub } 24[.]} & \sim \operatorname{normal}(0,2) \\
\mu_{\text {incub31. }}[.] & \sim \operatorname{normal}(0,2) \\
\sigma_{\text {incub24 }}[.] & \sim \operatorname{uniform}(\min =0, \max =10) \\
\sigma_{\text {incub31. }}[.] & \sim \operatorname{uniform}(0,10)
\end{aligned}
$$

and for all $j \in\{1 \ldots T\}$ :

$$
\begin{aligned}
& d \lambda_{0}(j) \sim \operatorname{gamma}\left(\text { mean }=d \lambda_{0}^{*}(j), \text { rate }=c\right) \\
& d \lambda_{0}^{*}(j)=r \times d t_{j}
\end{aligned}
$$


with $c=0.001$ and $r=0.1$. We used the first replication block and the effect of the stock strain in the $24^{\circ} \mathrm{C}$ incubation as the references:

$$
\begin{aligned}
\beta_{b l k}[1] & =1 \\
\mu_{\text {incub } 24}[a n c] & =1
\end{aligned}
$$

We ran four chains in parallel with the JAGS MCMC sampler for 10000 iterations 650 per chain, of which the first 5000 were discarded as burn-in. Model convergence and chain mixing was assessed by visual examination of trace plots and calculation of $\hat{R}$ 652 values.

\section{Selection of m6A in non-fully methylated GATC motifs}

654 The method to identify GATC loci which were not fully methylated in our dataset was reported in another study (Bruneaux et al. (2019) and Supplementary Figure S7).

656 Briefly, we calculated for each GATC locus the distance between the point defined by its methylated fractions on the plus and minus strand and the point corresponding to 658 full methylation on both strands $(1,1)$. We then defined the set of partially methylated GATC loci of interest as the loci which deviated from the point of full methylation

660 more than four times the average quadratic distance to $(1,1)$ in at least one sequenced strain (Supplementary Figure S7). 


\section{Supplementary tables}

\begin{tabular}{|c|c|c|c|c|}
\hline \multirow{2}{*}{ Prophage ID } & \multicolumn{2}{|c|}{ Position in stock strain genome } & \multirow{2}{*}{$\begin{array}{l}\text { Size (kb) } \\
(\text { PHAST) } \\
\end{array}$} & \multirow{2}{*}{$\begin{array}{c}\text { Completeness } \\
\text { (PHAST) }\end{array}$} \\
\hline & PHAST & PHASTER & & \\
\hline 1 & $521990-535146$ & $521990-535146$ & 13.2 & incomplete \\
\hline 2 & $622586-654808$ & - & 32.2 & incomplete \\
\hline 3 & $949738-979420$ & - & 29.7 & incomplete \\
\hline $4(\mathrm{KSP} 20)$ & $1970982-2003867$ & $1970982-2003867$ & 32.9 & intact \\
\hline 5 & $3451823-3468581$ & $3451823-3468581$ & 16.8 & intact \\
\hline 6 & $3914469-3946913$ & $3914469-3946913$ & 32.4 & incomplete \\
\hline 7 & $4427283-4461768$ & $4423686-4461768$ & 34.5 & intact \\
\hline
\end{tabular}

Supplementary Table S1: In-silico detection of prophage sequences in S. marcescens stock strain genome. For prophages predicted both by PHAST and PHASTER, completeness was consistent between the two tools. Predictions were run the PHAST and PHASTER servers on 2019-04-21.

\begin{tabular}{ccc}
\hline Type & Location & Effect on protein sequence \\
\hline \multirow{2}{*}{ Indels $\left(31,30^{*}\right)$} & coding regions $\left(13,12^{*}\right)$ & $\begin{array}{c}\text { frame shift }\left(11,10^{*}\right) \\
\text { no frame shift }\left(2,2^{*}\right)\end{array}$ \\
\cline { 2 - 3 } & non-coding regions $\left(18,18^{*}\right)$ & \\
\hline $\operatorname{SNPs}\left(23,13^{*}\right)$ & coding regions $\left(17,9^{*}\right)$ & $\begin{array}{c}\text { non-synonymous }\left(14,8^{*}\right) \\
\text { synonymous }\left(3,1^{*}\right)\end{array}$ \\
\cline { 2 - 3 } & non-coding regions $\left(6,4^{*}\right)$ & \\
\hline
\end{tabular}

Supplementary Table S2: Summary of genetic variants across the reference and the 28 evolved strains. Counts are given in parentheses. Numbers with asterisk are counts when the variants comprising haplotype $a$ are not taken into account. 


\section{APPENDIX}

Evolution in phage-bacteria-insect system

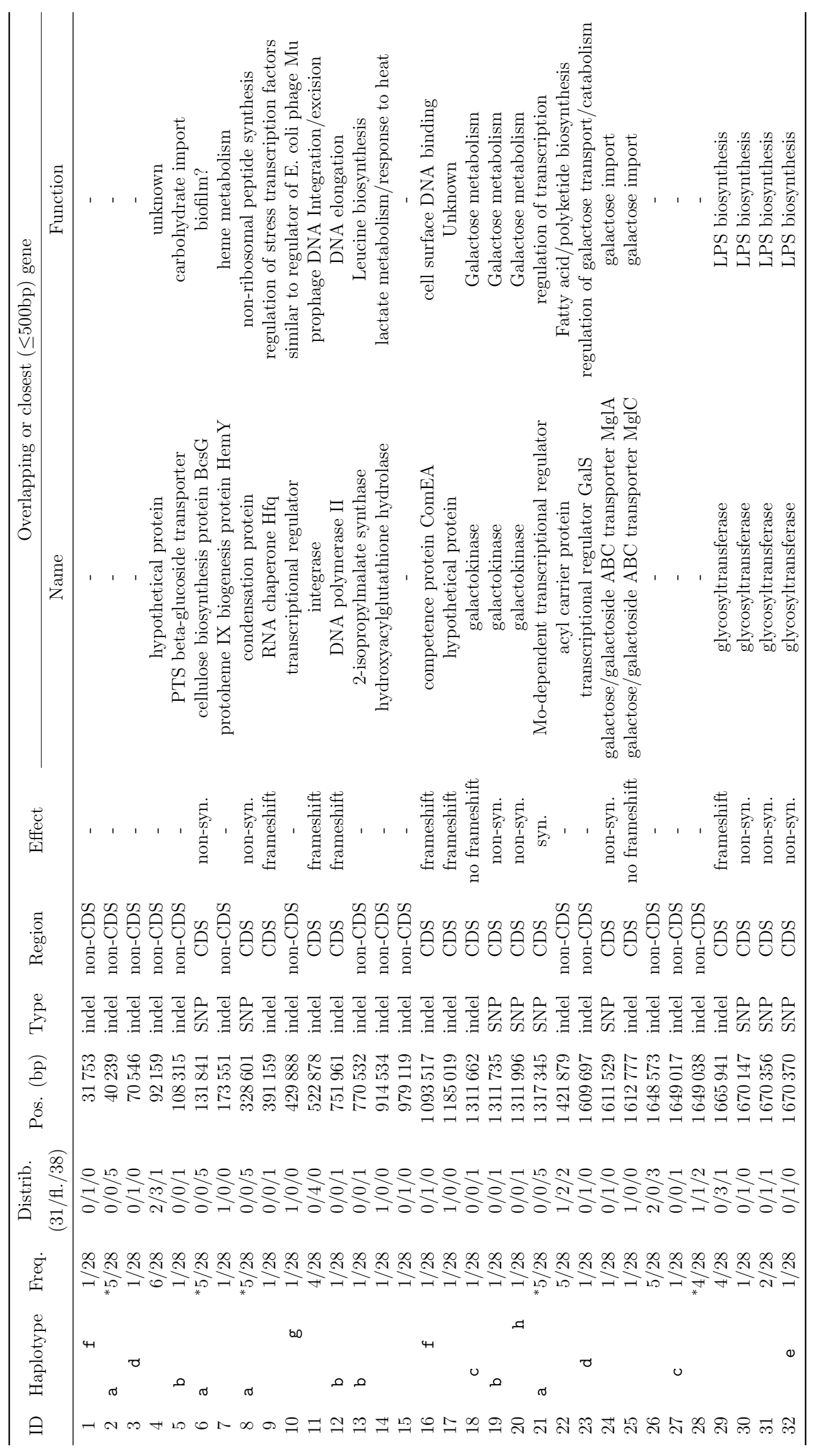






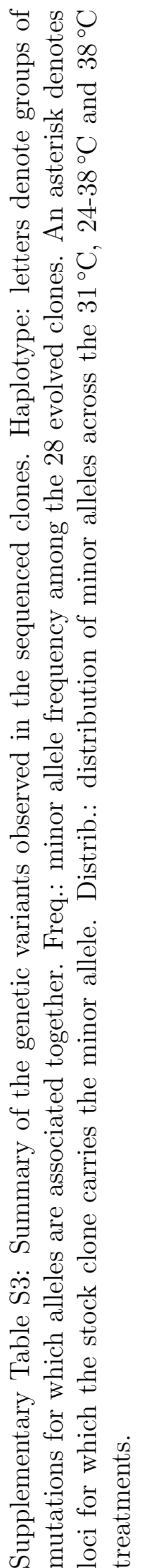




\begin{tabular}{|c|c|c|}
\hline Target & Name & Sequence \\
\hline Prophage 1 & $\begin{array}{l}\text { ph1-F } \\
\text { ph1-R }\end{array}$ & $\begin{array}{l}\text { 5'-CGGACGTTCTTTCCTCTGCT-3' } \\
\text { 5'-AGCTCTGCAGCGTTATCCAG-3' }\end{array}$ \\
\hline Prophage 2 & & $\begin{array}{l}5^{\prime} \text {-GGCGGGGTTATCACACAGTT-3' } \\
5^{\prime} \text {-CGCTCTGGTTAGACACCTCG-3' }\end{array}$ \\
\hline Prophage 3 & & $\begin{array}{l}\text { 5'-GAGGGGAGGCAGGAATGAAA-3' } \\
\text { 5'-CGCCACCCGCTGATAAAGAG-3' }\end{array}$ \\
\hline Prophage 4 (KSP20) & $\begin{array}{l}\text { ph4-F } \\
\text { ph4-R }\end{array}$ & $\begin{array}{l}\text { 5'-CTTTGGTTCAGGCGTCATGG-3' } \\
\text { 5'-GTAAACCAGTCCCACACGCT-3' }\end{array}$ \\
\hline Prophage 5 & $\begin{array}{l}\text { ph5-F } \\
\text { ph5-R }\end{array}$ & $\begin{array}{l}\text { 5'-GCCACATATCCCAGCGTTGA-3' } \\
\text { 5'-ATGGCAAGCCACAGATAGGT-3' }^{\prime}\end{array}$ \\
\hline Prophage 6 & $\begin{array}{l}\text { ph6-F } \\
\text { ph6-R }\end{array}$ & $\begin{array}{l}\text { 5'-GTGCCGAAGGAATGGCCTTA-3' } \\
\text { 5'-CTGAAATTGCTTCGCGCCAT-3' }\end{array}$ \\
\hline Prophage 7 & $\begin{array}{l}\text { ph7-F } \\
\text { ph7-R }\end{array}$ & $\begin{array}{l}\text { 5'-GTCAAAGGGGTTAAGCTCGC-3' } \\
5^{\prime} \text {-GAACAGAACGGCGCACTACA-3' }\end{array}$ \\
\hline Bacterial gene & $\begin{array}{l}\text { purA2-F } \\
\text { purA2-R }\end{array}$ & $\begin{array}{l}\text { 5'-ATGTGGATTACGTGCTGGGC-3' } \\
\text { 5'-CACAGGTATTCGCCGGTTTC-3' }\end{array}$ \\
\hline
\end{tabular}

Supplementary Table S4: Sequences of the primers used in the qPCR quantification of prophages and chromosomal DNA. The purA2-F/R primers are targeting the chromosomal, non-prophage-related bacterial gene for adenylosuccinate synthetase. 


\begin{tabular}{|c|c|c|c|c|c|c|c|c|c|}
\hline \multirow{2}{*}{ Gene ID } & \multirow{2}{*}{$\rho$} & \multirow{2}{*}{$p$-value } & \multirow{2}{*}{ Description } & \multicolumn{6}{|c|}{ Has a role in } \\
\hline & & & & $\operatorname{Tr}$ & Met & Nut & CWS & MBA & Vir \\
\hline 381 & -0.61 & 0.00043 & fimbrial biogenesis outer membrane usher protein & & & & & $\bullet$ & $\bullet$ \\
\hline 636 & -0.53 & 0.0029 & sugar phosphate isomerase/epimerase & & $\bullet$ & $\bullet$ & & & \\
\hline 2737 & -0.53 & 0.0029 & TetR/AcrR family transcriptional regulator & $\bullet$ & & & & & \\
\hline 3318 & -0.53 & 0.003 & glycerol-3-phosphate transporter & & & $\bullet$ & & & $\bullet$ \\
\hline 4357 & -0.53 & 0.003 & $\begin{array}{l}\text { anaerobic glycerol-3-phosphate dehydrogenase } \\
\text { subunit A }\end{array}$ & & $\bullet$ & & & & \\
\hline 4695 & -0.53 & 0.0033 & MFS transporter & & & $\bullet$ & $\bullet$ & & $\bullet$ \\
\hline
\end{tabular}

Supplementary Table S5: Epigenetic association between genes and phage activation in $24 / 24^{\circ} \mathrm{C}$. A negative $\rho$ means that phage activation increases as methylated fraction decreases. $\rho$ and $p$-values are given for Spearman's correlation coefficient between m6A methylation fraction and phenotypic trait value. Tr, regulation of transcription; Met, metabolism; Nut, nutrient transport; CWS, cell wall structure; MBA, motility/biofilm formation/adherence/quorum sensing; Vir, virulence.

\begin{tabular}{|c|c|c|c|c|c|c|c|c|c|}
\hline \multirow{2}{*}{ Gene ID } & \multirow{2}{*}{$\rho$} & \multirow{2}{*}{$p$-value } & \multirow{2}{*}{ Description } & \multicolumn{6}{|c|}{ Has a role in } \\
\hline & & & & $\operatorname{Tr}$ & Met & Nut & CWS & MBA & Vir \\
\hline 4647 & -0.63 & 0.00023 & hypothetical protein & & & & & & \\
\hline 3829 & -0.63 & 0.00023 & Fe-S cluster assembly scaffold SufA & & & & & & \\
\hline 636 & -0.59 & 0.00067 & sugar phosphate isomerase/epimerase & & - & $\bullet$ & & & \\
\hline 2737 & -0.59 & 0.00067 & TetR/AcrR family transcriptional regulator & - & & & & & \\
\hline 164 & -0.57 & 0.0012 & transcriptional regulator $\mathrm{LeuO}$ & $\bullet$ & & & & $\bullet$ & $\bullet$ \\
\hline 2366 & -0.54 & 0.0022 & thiamine biosynthesis protein ThiF & & & & & & \\
\hline 1244 & -0.54 & 0.0022 & hypothetical protein & & & & & & \\
\hline 1066 & 0.54 & 0.0024 & MFS transporter & & & & & & \\
\hline 611 & 0.54 & 0.0024 & class II histone deacetylase & & & & & & \\
\hline
\end{tabular}

Supplementary Table S6: Epigenetic association between genes and phage activation in $24 / 38^{\circ} \mathrm{C}$. A negative $\rho$ means that phage activation increases as methylated fraction decreases. $\rho$ and $p$-values are given for Spearman's correlation coefficient between m6A methylation fraction and phenotypic trait value. Tr, regulation of transcription; Met, metabolism; Nut, nutrient transport; CWS, cell wall structure; MBA, motility/biofilm formation/adherence/quorum sensing; Vir, virulence. 
bioRxiv preprint doi: https://doi.org/10.1101/850248; this version posted November 21, 2019. The copyright holder for this preprint (which was not certified by peer review) is the author/funder, who has granted bioRxiv a license to display the preprint in perpetuity. It is made available under aCC-BY 4.0 International license.

\begin{tabular}{|c|c|c|c|c|c|c|c|c|c|}
\hline \multirow{2}{*}{ Gene ID } & \multirow{2}{*}{$\rho$} & \multirow{2}{*}{$p$-value } & \multirow{2}{*}{ Description } & \multicolumn{6}{|c|}{ Has a role in } \\
\hline & & & & $\operatorname{Tr}$ & Met & Nut & CWS & MBA & Vir \\
\hline 4638 & 0.59 & 0.00079 & acyl carrier protein & & $\bullet$ & & $\bullet$ & $\bullet$ & $\bullet$ \\
\hline 4431 & 0.59 & 0.00079 & hypothetical protein & & & & & & \\
\hline 2635 & 0.58 & 0.00093 & cytoplasmic protein & & & & & & $\bullet$ \\
\hline 698 & 0.58 & 0.00093 & hypothetical protein & & & & & & $\bullet$ \\
\hline 4636 & 0.58 & 0.0012 & hypothetical protein & & & $\bullet$ & & & \\
\hline 3247 & 0.58 & 0.0012 & catalase & & $\bullet$ & & & & $\bullet$ \\
\hline 1898 & 0.53 & 0.0032 & hypothetical protein & & & & & & \\
\hline 2341 & 0.53 & 0.0032 & lipid A biosynthesis lauroyl acyltransferase & & & & $\bullet$ & $\bullet$ & $\bullet$ \\
\hline 2897 & 0.52 & 0.0038 & AraC family transcriptional regulator & $\bullet$ & & & & & \\
\hline
\end{tabular}

Supplementary Table S7: Epigenetic association between genes and phage activation in $31 / 31^{\circ} \mathrm{C}$. A negative $\rho$ means that phage activation increases as methylated fraction decreases. $\rho$ and $p$-values are given for Spearman's correlation coefficient between m6A methylation fraction and phenotypic trait value. Tr, regulation of transcription; Met, metabolism; Nut, nutrient transport; CWS, cell wall structure; MBA, motility/biofilm formation/adherence/quorum sensing; Vir, virulence.

\begin{tabular}{|c|c|c|c|c|c|c|c|c|c|}
\hline \multirow{2}{*}{ Gene ID } & \multirow{2}{*}{$\rho$} & \multirow{2}{*}{$p$-value } & \multirow{2}{*}{ Description } & \multicolumn{6}{|c|}{ Has a role in } \\
\hline & & & & $\operatorname{Tr}$ & Met & Nut & CWS & MBA & Vir \\
\hline 4269 & -0.6 & 0.00056 & leucine efflux protein LeuE & & & $\bullet$ & & & \\
\hline 2690 & -0.6 & 0.00056 & $\begin{array}{l}\text { bifunctional DNA-binding transcriptional } \\
\text { regulator/O6-methylguanine-DNA } \\
\text { methyltransferase Ada }\end{array}$ & & & & & & \\
\hline 4695 & -0.6 & 0.00064 & MFS transporter & & & $\bullet$ & $\bullet$ & & $\bullet$ \\
\hline 605 & -0.58 & 0.00091 & serine transporter & & & $\bullet$ & & & \\
\hline 482 & -0.57 & 0.0013 & anaerobic ribonucleoside-triphosphate reductase & & & & & $\bullet$ & $\bullet$ \\
\hline 2481 & -0.57 & 0.0013 & restriction endonuclease & & & & & & \\
\hline 4267 & -0.56 & 0.002 & cell division inhibitor SulA & $\bullet$ & $\bullet$ & & & & $\bullet$ \\
\hline 4038 & -0.56 & 0.002 & porin OmpA & & & & $\bullet$ & $\bullet$ & $\bullet$ \\
\hline 1281 & -0.55 & 0.0019 & Fe-S assembly protein IscX & & $\bullet$ & & & & $\bullet$ \\
\hline 628 & -0.55 & 0.0019 & aminopeptidase PepB & & $\bullet$ & & & & \\
\hline 4388 & -0.53 & 0.003 & DUF1471 domain-containing protein & & & & & $\bullet$ & $\bullet$ \\
\hline 2289 & -0.52 & 0.0038 & D-alanyl-D-alanine endopeptidase & & & & & $\bullet$ & \\
\hline 2590 & -0.52 & 0.0039 & hypothetical protein & & & & & & \\
\hline 1765 & -0.51 & 0.0046 & gamma-glutamyltransferase & & $\bullet$ & & & & $\bullet$ \\
\hline 1382 & -0.51 & 0.0047 & hypothetical protein & & & & & & \\
\hline 999 & -0.51 & 0.0047 & ASCH domain-containing protein & & & & & & \\
\hline 104 & -0.51 & 0.005 & hypothetical protein & & & & & & \\
\hline 643 & -0.51 & 0.005 & type 1 fimbrial protein & & & & & $\bullet$ & $\bullet$ \\
\hline
\end{tabular}

Supplementary Table S8: Epigenetic association between genes and phage activation in $38 / 24^{\circ} \mathrm{C}$. A negative $\rho$ means that phage activation increases as methylated fraction decreases. $\rho$ and $p$-values are given for Spearman's correlation coefficient between m6A methylation fraction and phenotypic trait value. Tr, regulation of transcription; Met, metabolism; Nut, nutrient transport; CWS, cell wall structure; MBA, motility/biofilm formation/adherence/quorum sensing; Vir, virulence. 


\begin{tabular}{|c|c|c|c|c|c|c|c|c|c|}
\hline \multirow{2}{*}{ Gene ID } & \multirow{2}{*}{$\rho$} & \multirow{2}{*}{$p$-value } & \multirow{2}{*}{ Description } & \multicolumn{6}{|c|}{ Has a role in } \\
\hline & & & & $\operatorname{Tr}$ & Met & Nut & CWS & MBA & Vir \\
\hline 1874 & -0.62 & 0.00034 & histidinol-phosphate transaminase & & $\bullet$ & & & & $\bullet$ \\
\hline 32 & -0.62 & 0.00034 & $\begin{array}{l}\text { bifunctional histidinol- } \\
\text { phosphatase/imidazoleglycerol-phosphate } \\
\text { dehydratase HisB }\end{array}$ & & $\bullet$ & & & & $\bullet$ \\
\hline 3372 & 0.59 & 0.00071 & Lrp/AsnC family transcriptional regulator & $\bullet$ & & & & & \\
\hline 4180 & 0.59 & 0.00071 & EamA/RhaT family transporter & & & $\bullet$ & & & \\
\hline 892 & -0.57 & 0.0011 & hypothetical protein & & & & & & \\
\hline 3235 & -0.57 & 0.0011 & type 1 fimbrial protein & & & & & & \\
\hline 1066 & 0.57 & 0.0011 & MFS transporter & & & & & & \\
\hline 611 & 0.57 & 0.0011 & class II histone deacetylase & & & & & & \\
\hline 3426 & 0.57 & 0.0012 & TonB system transport protein ExbD & & & $\bullet$ & & $\bullet$ & $\bullet$ \\
\hline 1639 & 0.53 & 0.0034 & GTPase & & & & & & \\
\hline 4269 & 0.52 & 0.004 & leucine efflux protein LeuE & & & $\bullet$ & & & \\
\hline 2690 & 0.52 & 0.004 & $\begin{array}{l}\text { bifunctional DNA-binding transcriptional } \\
\text { regulator/O6-methylguanine-DNA } \\
\text { methyltransferase Ada }\end{array}$ & & & & & & \\
\hline 3992 & 0.51 & 0.0044 & energy transducer TonB & & & $\bullet$ & & & $\bullet$ \\
\hline
\end{tabular}

Supplementary Table S9: Epigenetic association between genes and phage activation in $38 / 38^{\circ} \mathrm{C}$. A negative $\rho$ means that phage activation increases as methylated fraction decreases. $\rho$ and $p$-values are given for Spearman's correlation coefficient between m6A methylation fraction and phenotypic trait value. Tr, regulation of transcription; Met, metabolism; Nut, nutrient transport; CWS, cell wall structure; MBA, motility/biofilm formation/adherence/quorum sensing; Vir, virulence. 


\begin{tabular}{|c|c|c|c|c|c|c|c|c|}
\hline \multirow{2}{*}{ Gene ID } & \multirow{2}{*}{$\rho$} & \multirow{2}{*}{$p$-value } & \multirow{2}{*}{ Description } & \multicolumn{5}{|c|}{ Has a role in } \\
\hline & & & & $\operatorname{Tr}$ Met & Nut & CWS & MBA & Vir \\
\hline 30 & 0.63 & 0.00027 & porin & & $\bullet$ & $\bullet$ & & \\
\hline 2870 & -0.54 & 0.003 & outer membrane usher protein & & & & $\bullet$ & $\bullet$ \\
\hline 147 & 0.54 & 0.0027 & type VI secretion system tip protein VgrG & & & & & $\bullet$ \\
\hline 4058 & -0.53 & 0.0034 & AraC family transcriptional regulator & $\bullet$ & & & & \\
\hline 1250 & -0.52 & 0.0042 & hypothetical protein & & & $\bullet$ & $\bullet$ & $\bullet$ \\
\hline
\end{tabular}

Supplementary Table S10: Epigenetic association between genes and virulence in waxmoth larvae at $24^{\circ} \mathrm{C}$ incubation. A negative $\rho$ means that the strain virulence increases as methylated fraction decreases. $\rho$ and $p$-values are given for Spearman's correlation coefficient between m6A methylation fraction and phenotypic trait value. Tr, regulation of transcription; Met, metabolism; Nut, nutrient transport; CWS, cell wall structure; MBA, motility/biofilm formation/adherence/quorum sensing; Vir, virulence.

\begin{tabular}{|c|c|c|c|c|c|c|c|c|c|}
\hline \multirow{2}{*}{ Gene ID } & \multirow{2}{*}{$\rho$} & \multirow{2}{*}{$p$-value } & \multirow{2}{*}{ Description } & \multicolumn{6}{|c|}{ Has a role in } \\
\hline & & & & $\operatorname{Tr}$ & Met & Nut & CWS & MBA & Vir \\
\hline 3838 & 0.62 & 0.00036 & hypothetical protein & & & & & & \\
\hline 2089 & 0.57 & 0.0011 & GGDEF domain-containing protein & & & & & $\bullet$ & \\
\hline 1837 & 0.57 & 0.0011 & aminopeptidase $\mathrm{N}$ & & $\bullet$ & & & & \\
\hline 4695 & 0.57 & 0.0014 & MFS transporter & & & $\bullet$ & $\bullet$ & & $\bullet$ \\
\hline 2917 & 0.57 & 0.0014 & DUF1304 domain-containing protein & & & & & & \\
\hline
\end{tabular}

Supplementary Table S11: Epigenetic association between genes and virulence in waxmoth larvae at $31^{\circ} \mathrm{C}$ incubation. A negative $\rho$ means that the strain virulence increases as methylated fraction decreases. $\rho$ and $p$-values are given for Spearman's correlation coefficient between m6A methylation fraction and phenotypic trait value. Tr, regulation of transcription; Met, metabolism; Nut, nutrient transport; CWS, cell wall structure; MBA, motility/biofilm formation/adherence/quorum sensing; Vir, virulence. 


\section{Supplementary figures}

PHAST



PHASTER

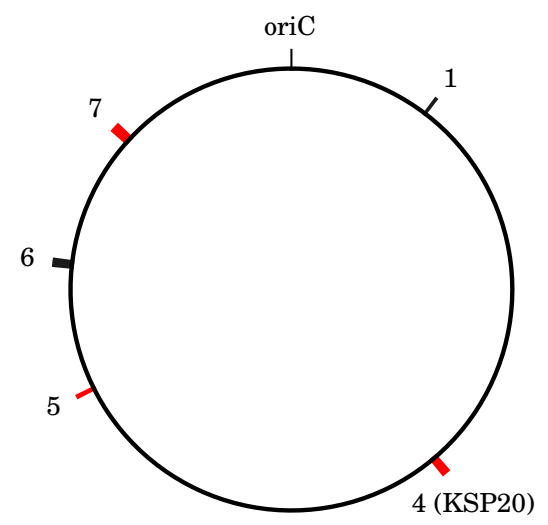

Incomplete prophage

Intact prophage

Supplementary Figure S1: Predicted prophages locations in S. marcescens stock strain genome. Labels correspond to the prophage identifiers as reported in Supplementary Table S1. Note that matching prophages have the same genomic coordinates between PHAST and PHASTER predictions, except for prophage 7 which has a slightly larger size as predicted by PHASTER. 


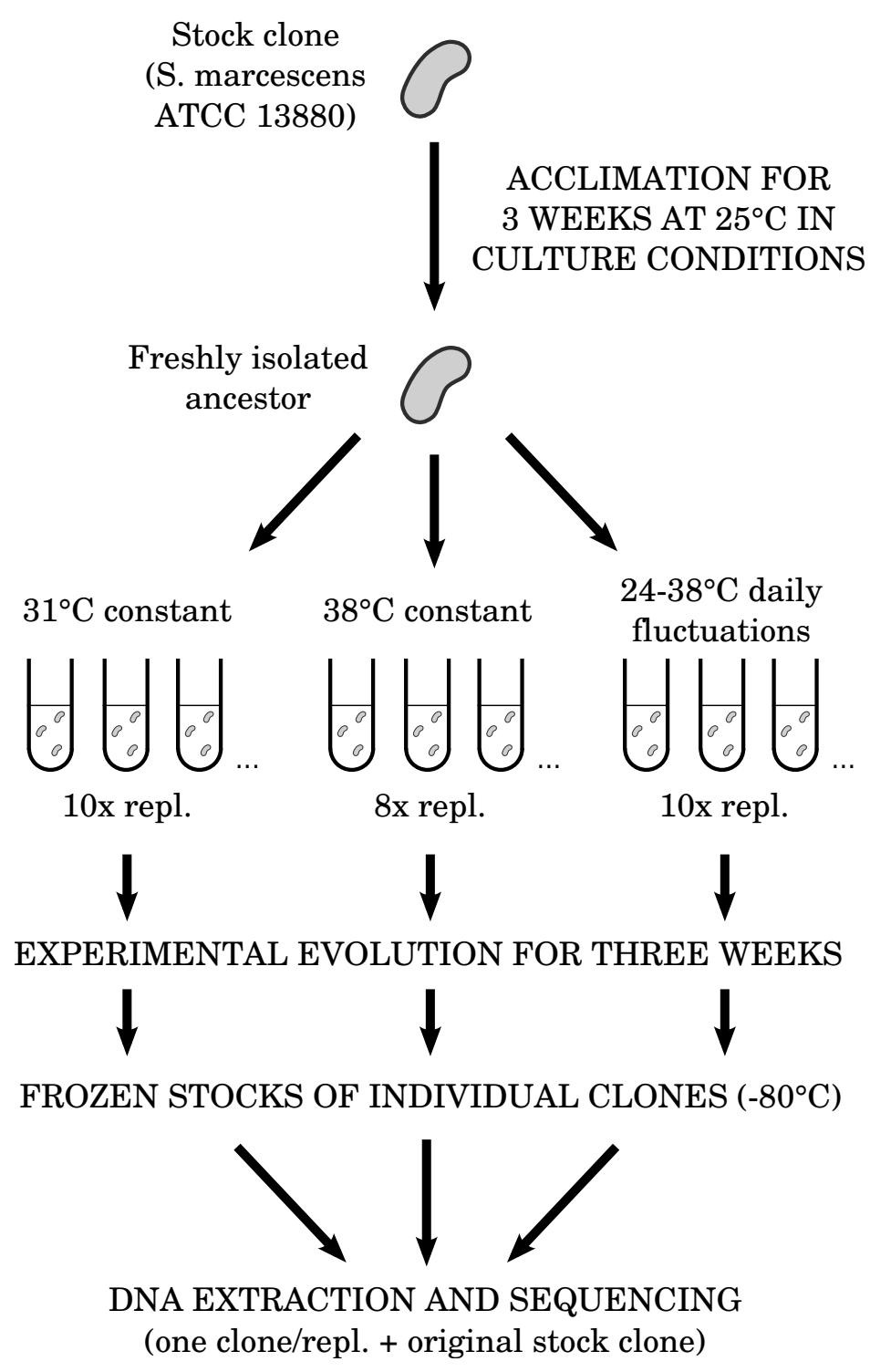

Supplementary Figure S2: Setup of the evolution experiment from which clones were isolated. One randomly selected clone per evolved population was used for sequencing. Details of the evolution experiment are available in Ketola et al. (2013). 


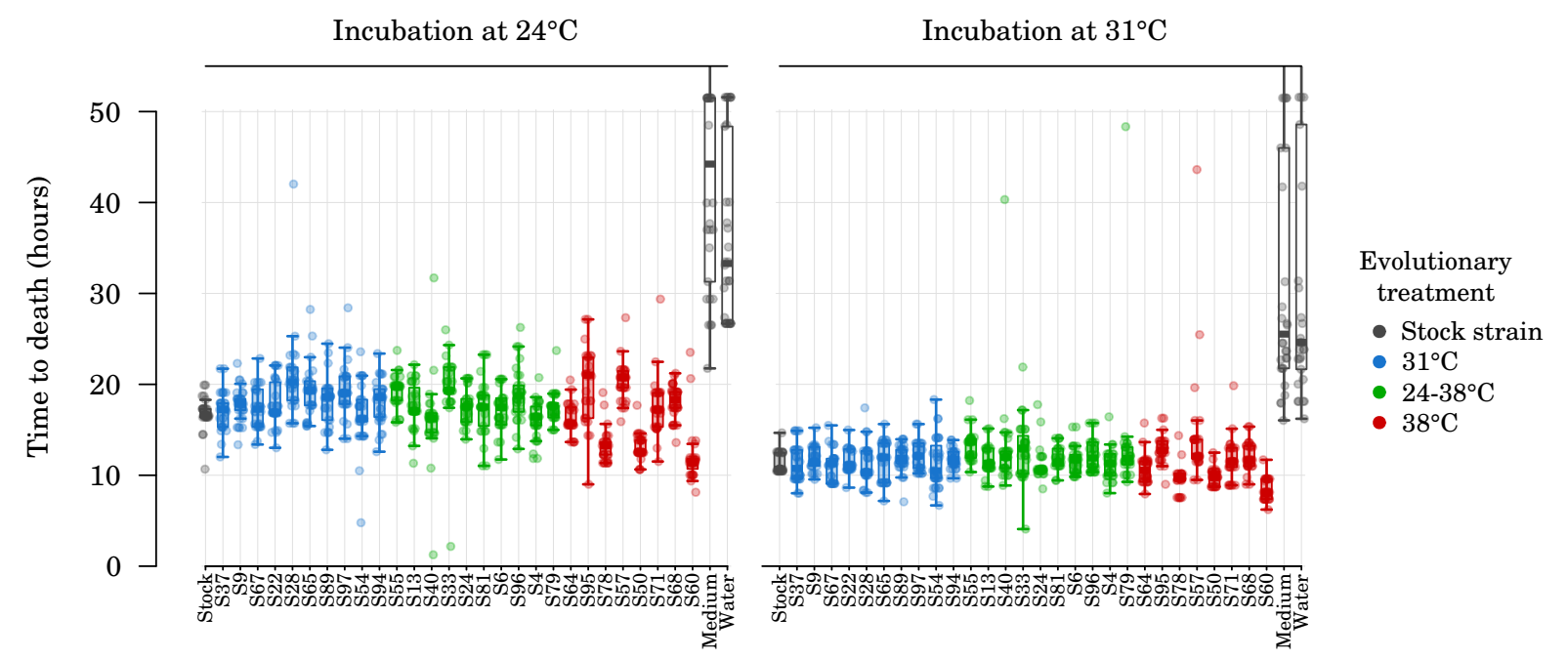

Supplementary Figure S3: Longevity of waxmoth larvae at two incubation temperatures after injection with experimental Serratia marcescens strains. Longevity is corrected for the effect of replication blocks, culture optical density and larva body mass. Dots are individual larvae. 
$\mathrm{A}$



$\mathrm{B}$

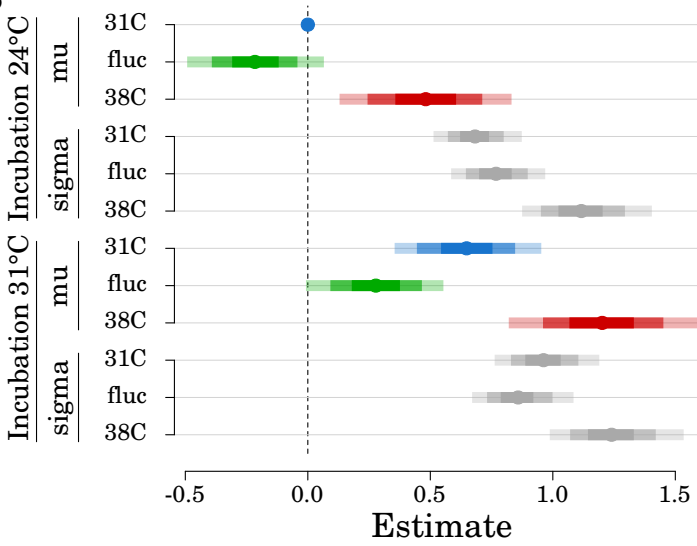

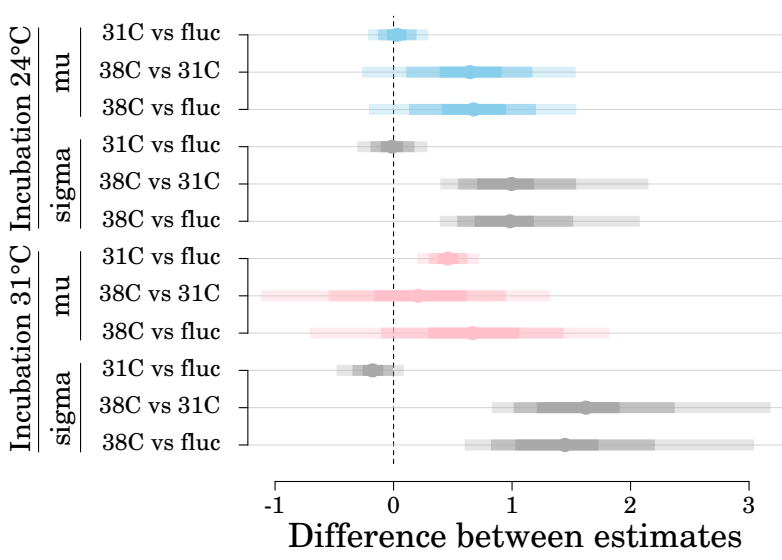

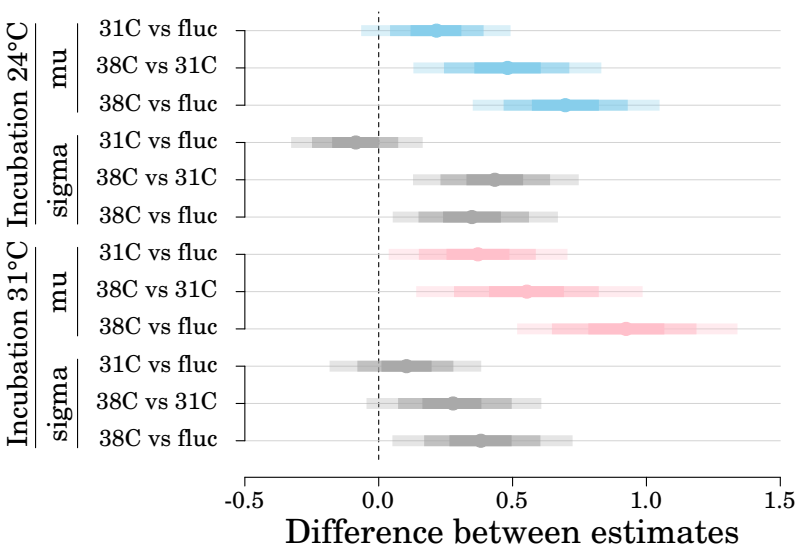

Supplementary Figure S4: Comparison of virulence estimates between sequenced clones and larger pool of evolved clones. A, estimates of mean and standard deviation of virulence in waxmoth larvae per evolutionary treatment, using the clones sequenced in this study. The data is the same as the data presented in Figure 2 of the main text. B, estimates of mean and standard deviation of virulence in waxmoth larvae per evolutionary treatment, using a larger pool of clones from the same evolution experiment that provided the sequenced clones (Ketola et al., 2013). Left panels, means and credible intervals (50, 80 and 95\%) for the parameter estimates. Right panels, means and credible intervals (50,80 and 95\%) for the differences between parameter estimates from pairs of evolutionary treatments. Note that in (A), the intercept for estimates was the stock strain, while in (B) it was the average virulence for strains evolved at $31^{\circ} \mathrm{C}$ under incubation at $24^{\circ} \mathrm{C}$. 


\section{APPENDIX \\ Evolution in phage-bacteria-insect system}
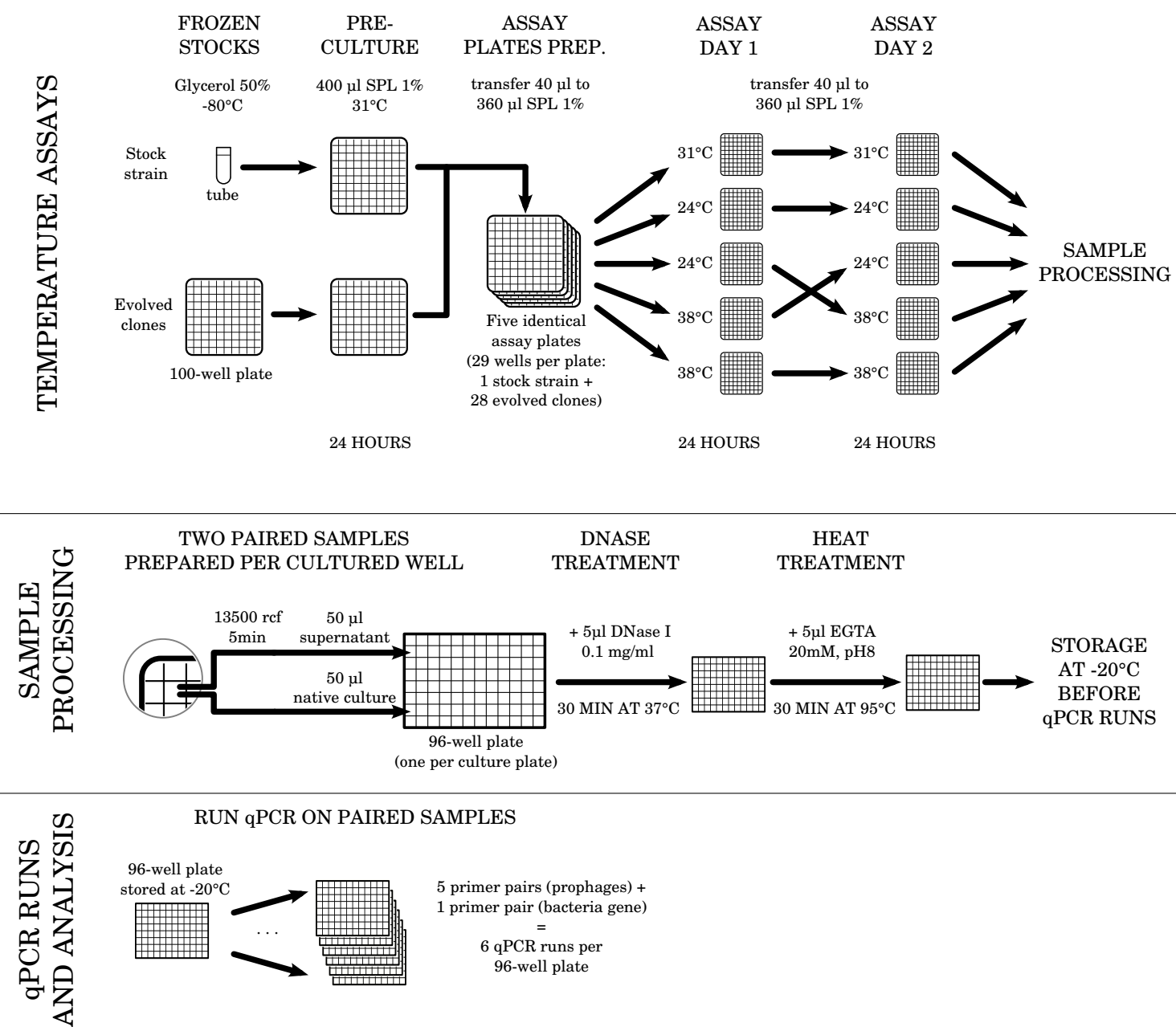

Supplementary Figure S5: Overview of the experimental protocol used in the prophage activation experiment. The prophage primers used in the $\mathrm{qPCR}$ runs were for prophages 1, 3, 4, 6 and 7, after preliminary experiments with the stock strain showed no detectable amount of extra-cellular DNA for prophages 2 and 5. 




Supplementary Figure S6: Simulation of qPCR results for different prophage activation rates $a$ and different centrifugation concentration factors $k . c_{\text {bact,nat }}, c_{\text {bact, sup }}$ and $c_{\text {pro,sup }}$ are the qPCR quantifications of DNA copie numbers for bacterial gene in native and supernatant samples and for prophage gene in supernatant samples, respectively. The colored lines show the predicted trajectories of $c_{\text {pro,sup }} / c_{\text {bact, nat }}$ versus $c_{\text {bact,sup }} / c_{\text {bact, nat }}$ from native samples (top-right corner) towards supernatant samples (to the left) as the centrifugation concentration factor $k$ decreases (i.e. as supernatant samples are more and more impoverished in bacteria cells). The shape of the trajectories depends on the activation rate of the prophage, i.e. on how many phage particles are present per bacteria cells in the native sample. The colored dots matching the colored predicted trajectories represent simulations of qPCR estimations which would be obtained as the centrifugation removes more and more bacteria cells from the supernatant, assuming a precision of the $\mathrm{Cq}$ values $\sigma_{c q}=0.48$ and triplicates qPCR measurements for each culture well, as was done in our experiment. As can be seen on the figure, the sensitivity threshold to detect phage particles decreases as the depletion of bacteria cells becomes more complete. However, even at $k$ values of $10^{-3}$, activation rates of $10^{-4}$ and lower are not distinguishable from the absence of induction. The red dots represent the results for a hypothetical culture, with the top-right dot representing the native sample and the bottom left dot representing the supernatant sample. 



Supplementary Figure S7: Detection of partially methylated GATC loci (figure taken from Bruneaux et al. (2019)). Distribution of methylated fractions of adenosines on boths DNA strands for GATC palindromes (showing data for all strains together). Left panel, all GATC palindromes shown; right panel, only GATC palindromes qualified as low methylation sites shown. The red arc in the left panel delimits the observations which are less four times the average quadratic distance to full methylation (point at $(1,1)$ ) away from full methylation. GATC palindromes are considered as low methylation sites if they lay outside this area (right panel). 